by

BNWL-CC -702

June 13, 1966

\title{
EVALUATION OF AN ULTRASONIC METHOD
NG REACTOR ALUMINUM PROCESS TUBE WALL THICMUTS \\ EVALUATION OF AN ULTRASONIC METHOD
FOR MEASURING REACTOR ALUMINUM PROCESS TUBE WALL THICKU
}

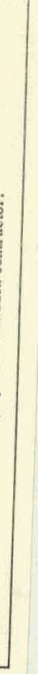

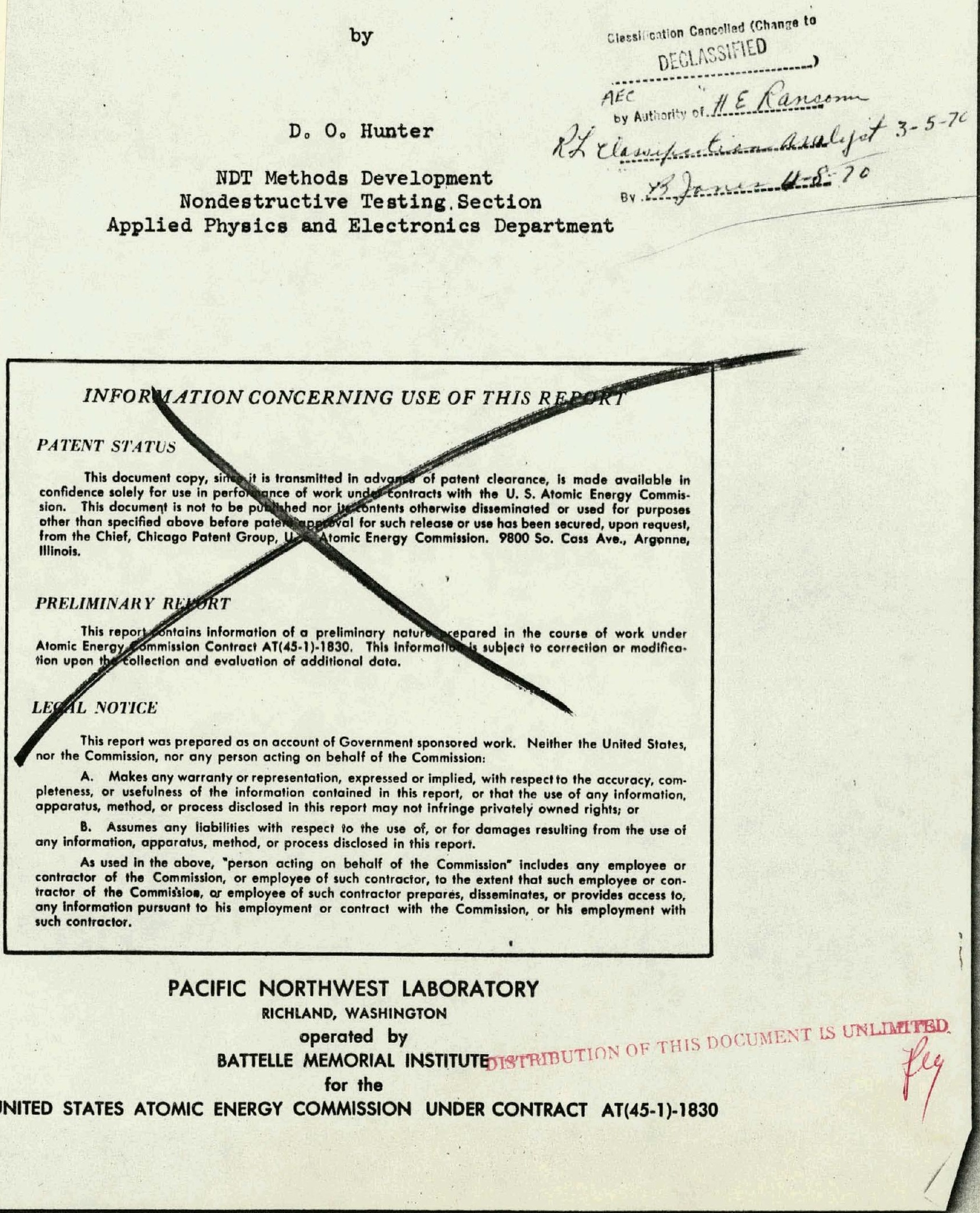




\section{DISCLAIMER}

This report was prepared as an account of work sponsored by an agency of the United States Government. Neither the United States Government nor any agency Thereof, nor any of their employees, makes any warranty, express or implied, or assumes any legal liability or responsibility for the accuracy, completeness, or usefulness of any information, apparatus, product, or process disclosed, or represents that its use would not infringe privately owned rights. Reference herein to any specific commercial product, process, or service by trade name, trademark, manufacturer, or otherwise does not necessarily constitute or imply its endorsement, recommendation, or favoring by the United States Government or any agency thereof. The views and opinions of authors expressed herein do not necessarily state or reflect those of the United States Government or any agency thereof. 


\section{DISCLAIMER}

Portions of this document may be illegible in electronic image products. Images are produced from the best available original document. 
DISTRIBUTION

Battelle-Northwest

R. E. Benham

I. J. Chockie

C. J. Denton (3)

G. E. Driver

G. C. Fullmer

G. F. Garlick

E. M. Kartchner

V. I. Neeley

E. H. O'Claire

J. To Russell

J. C. Spanner (2)

W. G. Spear

D. C. Worlton (2)

Technical Files (3)
Bidg. Area

3201 ' 3000

$3706 \quad 300$

$326 \quad 300$

$326 \quad 300$

3706 . 300

326.300

$326 \quad 300$

326 . 300

$306 \quad 300$

$326, \quad 300$

$326: 300$

$329 \quad 300$

$326 \cdot 300$

3706 . 300

\section{Douglas United Nuclear}

T. W. Ambrose

C. E. Bowers (5)

T. L. Deobold

A. K. Hardin

C. G. Lewis

R. J. Nicklas

C. B. Organ

R. W. Reld

D. E. Strege

1704-H 100-H

$1706-\mathrm{K} \quad 100-\mathrm{K}$

1720-K 100-K

1704-D 100-D

1720-K . 1.00-K

1706-KE 100-K

1706-K 100-K

1760-D 100-D

1706-K 100-K

Extra (10) 


\section{EVALUATION OF AN ULTRASONIC METHOD FOR MEASURING REACTOR}

\section{ALUMINUM PROCESS TUBE WALL THICKNESS}

D. 0 . Hunter

INTRODUCTION

Reactor aluminum process tubes are subjected to a variety of unf form and localized corrosion and mechanical damage thinning mechanisms. (1) If undetected, thinning can lead to eventual penetration of the tube wall and consequent water leakage which in turn causes accelerated corrosion thinning of the tube exterlors. For this and other reasons, suspect tubes are replaced when nondestructive measurements have forecasted the end of usable tube life.

Eddy current methods (Probolog) have " for some time, been used to detect excessive thinning. (2) Unfortunately, at any given cross section of a tube, the wall thickness of the entire annulus is averaged, thus preventing identification of top or bottom corrosion and furthermore preventing identification of heavy localized thinning from light uniform thinning. An eddy current sector gage method was developed to enable detection of localized areas, (3) but failed to live up to expectations in reactor trials.

Ultrasonic methods were then considered ${ }^{(4)}$ and found to have some apparent advantages over ediy current methoda: (I) capalle uf making meāiurements on localized areas. (2) relatively insensitive to temperature fluctuations, (3) not affected by the presence of graphite around the outer surface of the tubes, (4) relatively insensitive to inhomogeneities of the aluminum, and (5) capable of making measurements within the regton of the "gun barrels". Pulse-echo ultrasonic techniques appeared to be preferable to resonance techniques since ourface roughness was expected and fast testing was required. An "off-the-shelf" plece of comercial equipment was available and the decision was made to lease 
the equipment for the purpose of establishing the feasibility of pulsemecho ultrasonic measurement methods. SUMMARY

Ultrasonic thickness measurements were made on three tubes at $D$ Reactor. Distorted echoes were received over substantial portions of each tube resulting In poor recordings for those portions. Despite" poor recordings, some interpretation was possible and estimated thicknesses correlated reasonably well whth actual measurements on two tubes removed and cut into pieces. Four heavily filmed pieces were ultrasonically examined before and after film removal. Both film and closely spaced corrosion pits were found to contribute to distortion and $108 \mathrm{~s}$ of echoes needed for thickness measurement. Erroneous readings will result during measurement of heavily filmed areas even if good echoes are returned. Error will be reduced by operating on back sur-. face echoes rather than a front and a back surface echo.' Oscilloscope Interpretation of RF pulse waveforms is preferable to a recorded readout?

Performance of the high resolution pulse-echo ultrasonic instrument can be improved through circuit modifications, but its greatest usefulness appears to be as a companion to, rather than a replacement of, the Probolog. CONCLUSIUNS

Corrosion product film and/or corrosion pits -- particularly closely spaced corrosion pits, i.e., when dimensions of pit and distance between adjacent pits approaches ultrasonic beam cross-section dimensions -- will distort echoes to the extent that continuous thickness readings throughout the length of a tube w1ll be impossible.

When surface conditions are favorable, measurement accuracy -- according to the instrument manufacturer and largely substantiated -- will be \pm 1 percent or better. Minimum aluminum thickness messurement ability is about 0.019 in. 
Testing speed of up to $24 \mathrm{ft} / \mathrm{min}$ is : possible although additional development would be needed to simultaneously test top and bottom areas using just one instrument. Circumferential width of a sector being tested is limited to about $0.080 \mathrm{in}$. for reasons related to transducer design. If sectors "wider than $0.080 \mathrm{in}$ are required, multiplë transducers on both top and bottom would be needed although a nominal increase in width may result from additional transducer development. Maximum length measured is the crystal beam dimension in the longitudinal direction, also about $0.080 \mathrm{in.}$ IN-REACTOR TUBE THICKNESS MEASUREMENT

\section{A. Procedure}

Multiple runs were made on each of three tubes -- \#1485, a relatively new core tube, and \#4573 and \#4583, relatively old fringe tubes. Each run consisted of a manual pull-through of the uitrasonic probe assembly beginning at about 4. to $5 \mathrm{ft}$ from the rear Van Stone flange and ending at about 7 to $9 \mathrm{ft}$ from the front Van Stone flange. Pull-through speed varied from $14 \mathrm{ft} / \mathrm{min}$ to $24 \mathrm{ft} / \mathrm{mln}$. Three crystals were mounted on the probe -a at $22-1 / 2^{\circ}, 180^{\circ}$. and $337-1 / 2^{\circ}$, referenced to the tube's top; (See Flgure 1 for crystal aiming geometry.) Only one crystal was electricaliy connected for each run. A number of runs for each crystal were required to optimlze the amplifier sensitivity setting as an evaluation of reproduclbility. Readout was recorded on a strip chart recorder.

\section{B. Results}

The greater part of all three tubes returned poor echoes to the extent that considerable interpretation was necessary. In general, better echoes were returned from upstream and middle portions than from downstream portions. The apparent dominant echo distorting condition was a multiple front surface reflection which caused readings considerably thinner than true thickness. 


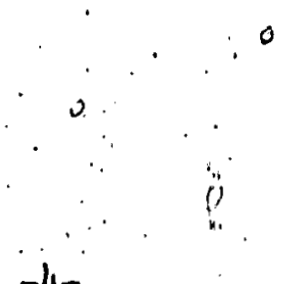

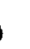

$-4-$

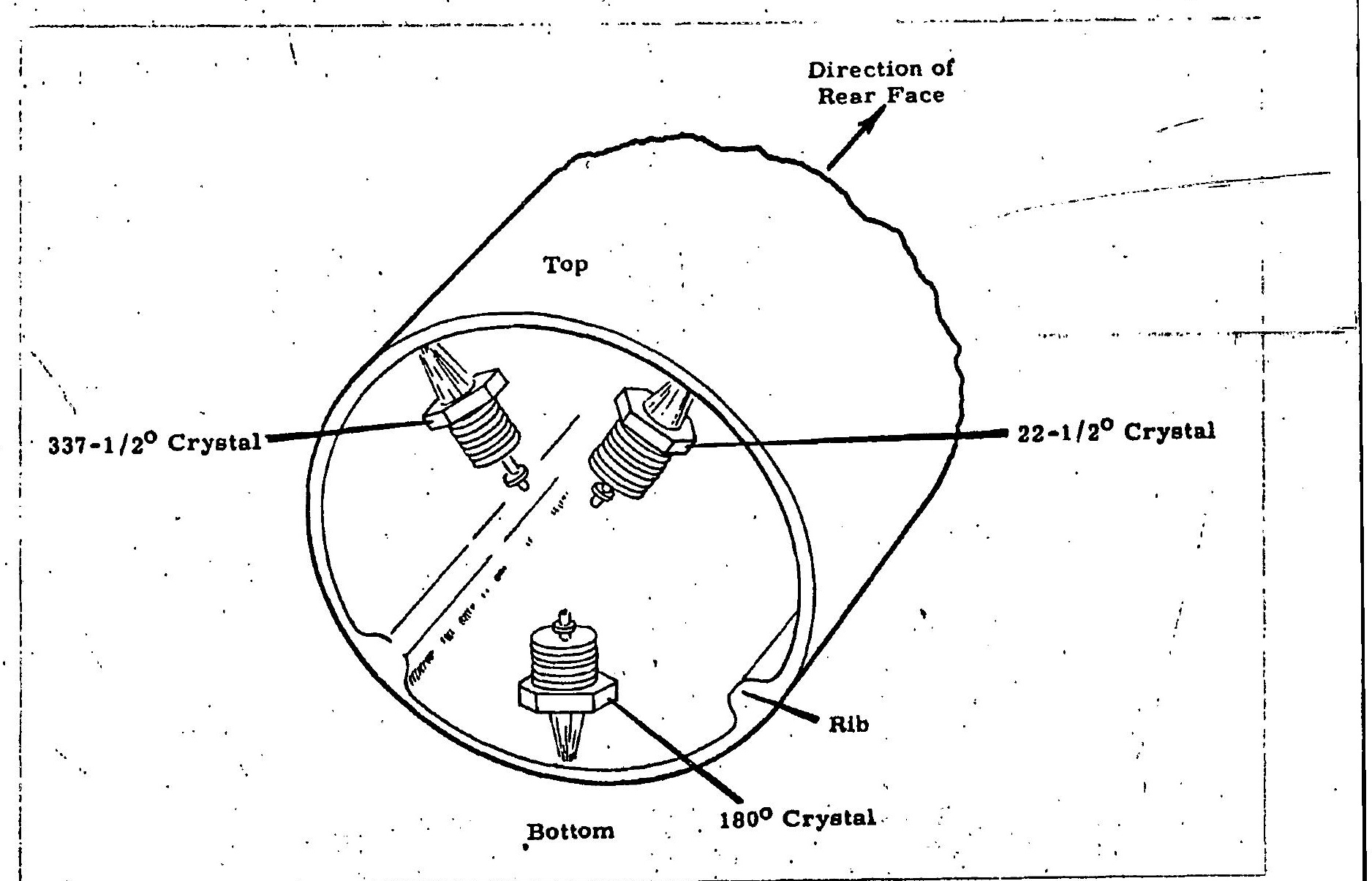

FIGURE 1!

Wall Thickness Measurement Ultrasonic Probe - Crystal Locations 
A rough front surface is the most likely cause of a multiple peaked reflection. Other signal distorting situations such as 1088 of all echoes and loss of echoes following the front surface echo also occurred. Readout under such circumstances would fluctuate from minimum to maximum. Interspersed with distorted echoes were enough good echoes that, with some interpretation, thicknegs estimates could be made.

Tube thickness profile charts are shown in Figures 2 through 7 . The dashed and crossed parts of the curves indicate regions where estimating was necessary. Actual measured thicknesses -- where avallable -- are also shownas comparison profile charts.

Examples of actual chart recordings are shown in Figures 8 through 17. Figures 8 and 9 are examples of good results; poor results are Just starting to appear at about $25 \mathrm{ft}$. These two figures also typify reproducibility of identical runs. Figures 10 and 11 are examples of poor results. After tube removal. 4 pieces from the region included in Figures 10 and 11 were ultrasonically re-examined. A discussion of results appears elsewhere in this report. Optimum sensitivity setting varles from crystal to crystal. The effect of too high sensitivity is seen when Figure 12 is compared to Figure 13 -- both recoralngs of the game region. The most likely cause of the fluctuations in the thin direction in Figure 12 is the rough surface echoes forming a multiple peaked front surface echo. Time measurements are incorrectly made on these peaks rather than on the front surface and back surface echoes. An explanation of rough surface effects on ingtrument readout follows under the DIscussion Section, page 23. The effect of too low sensitivity is shown in Figure 14. The excursions in the thick direction are caused by loss of echoes subsequent to the front surface echo. Recordings of tube \# 1485, the one 


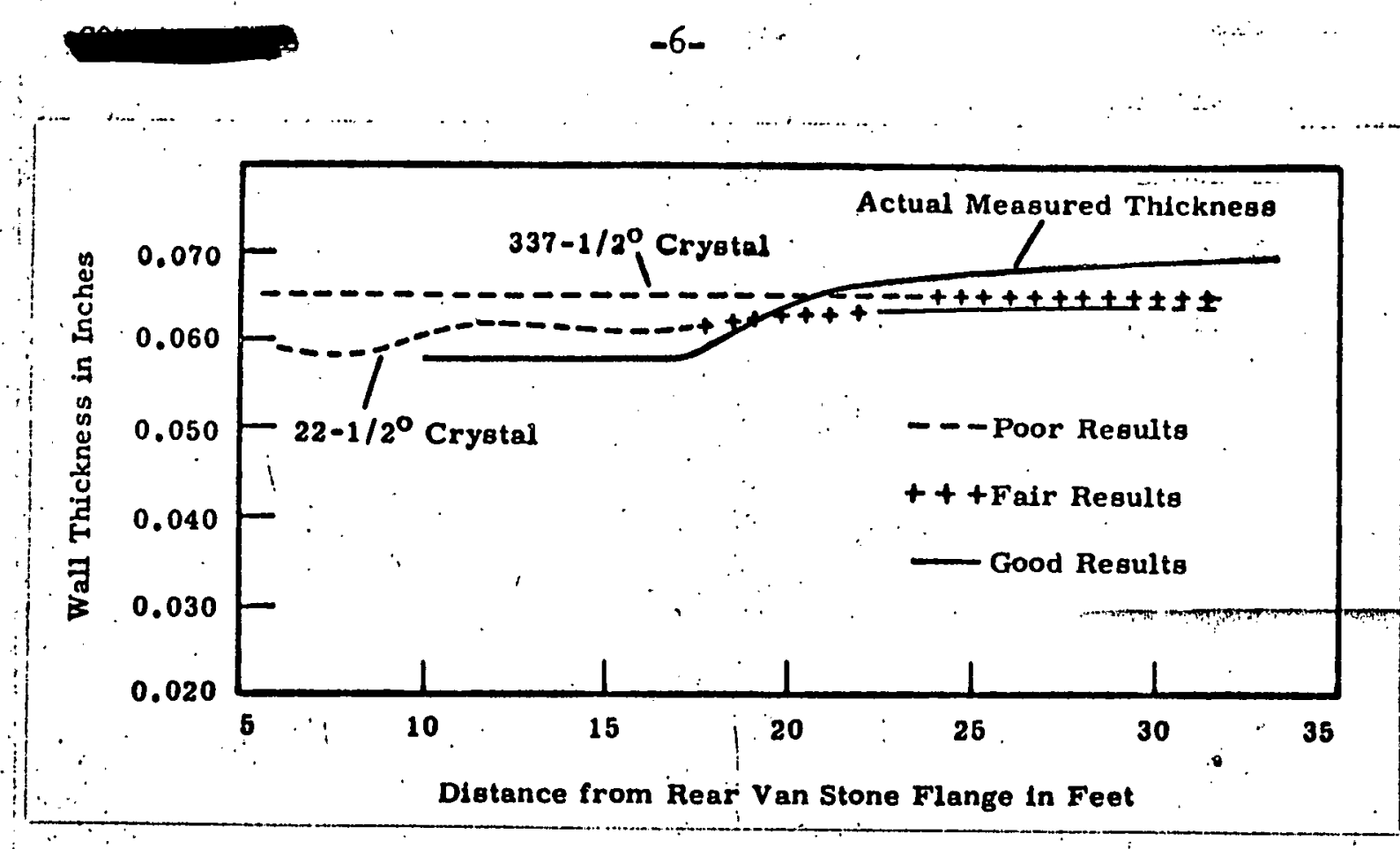

\section{FIGURE 2}

Thickness Profile, Top - Tube No. 4573-D

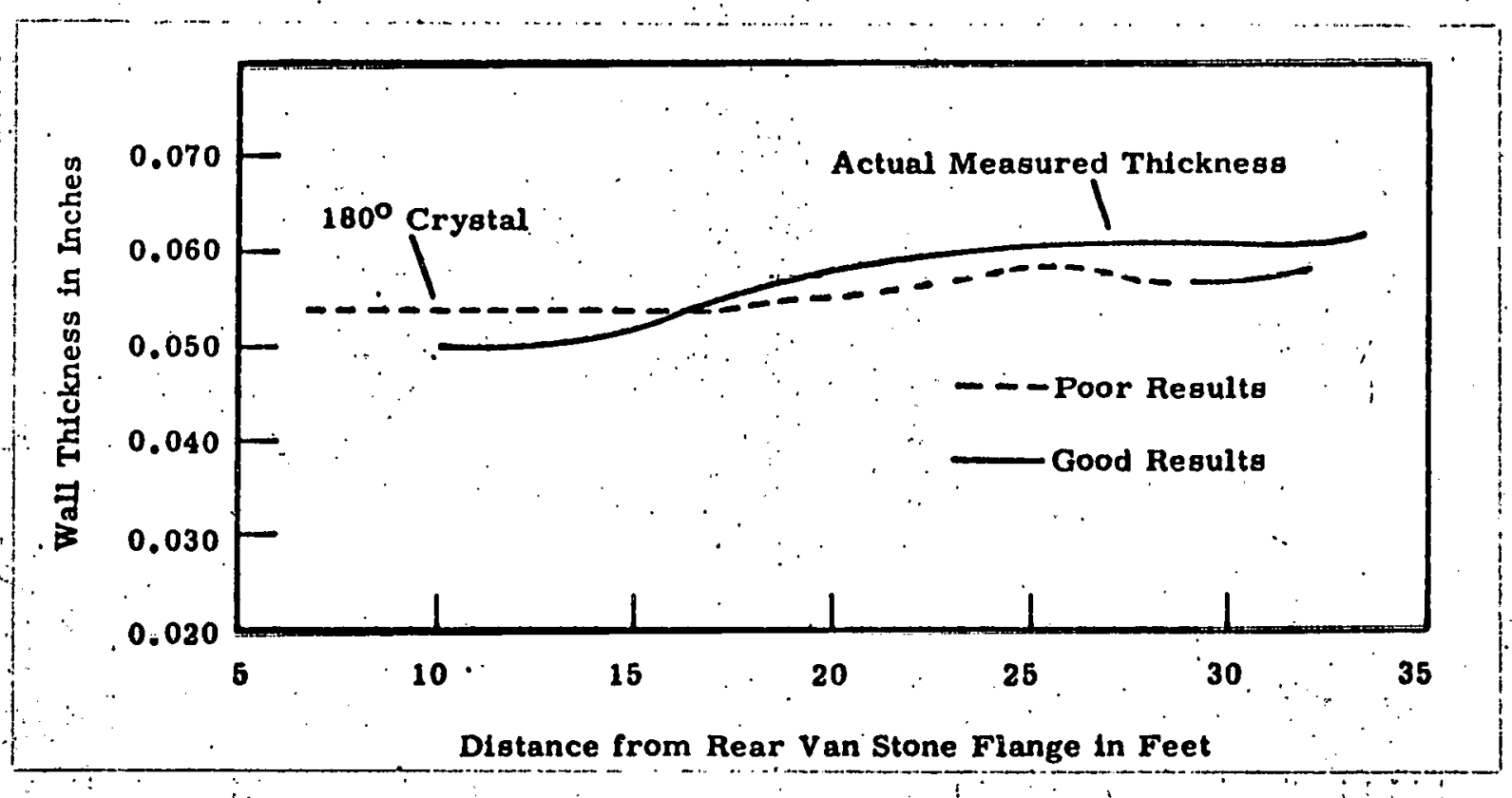
FIGURE 3

Thickness Profile, Bottom - Tube No. 4573-D 

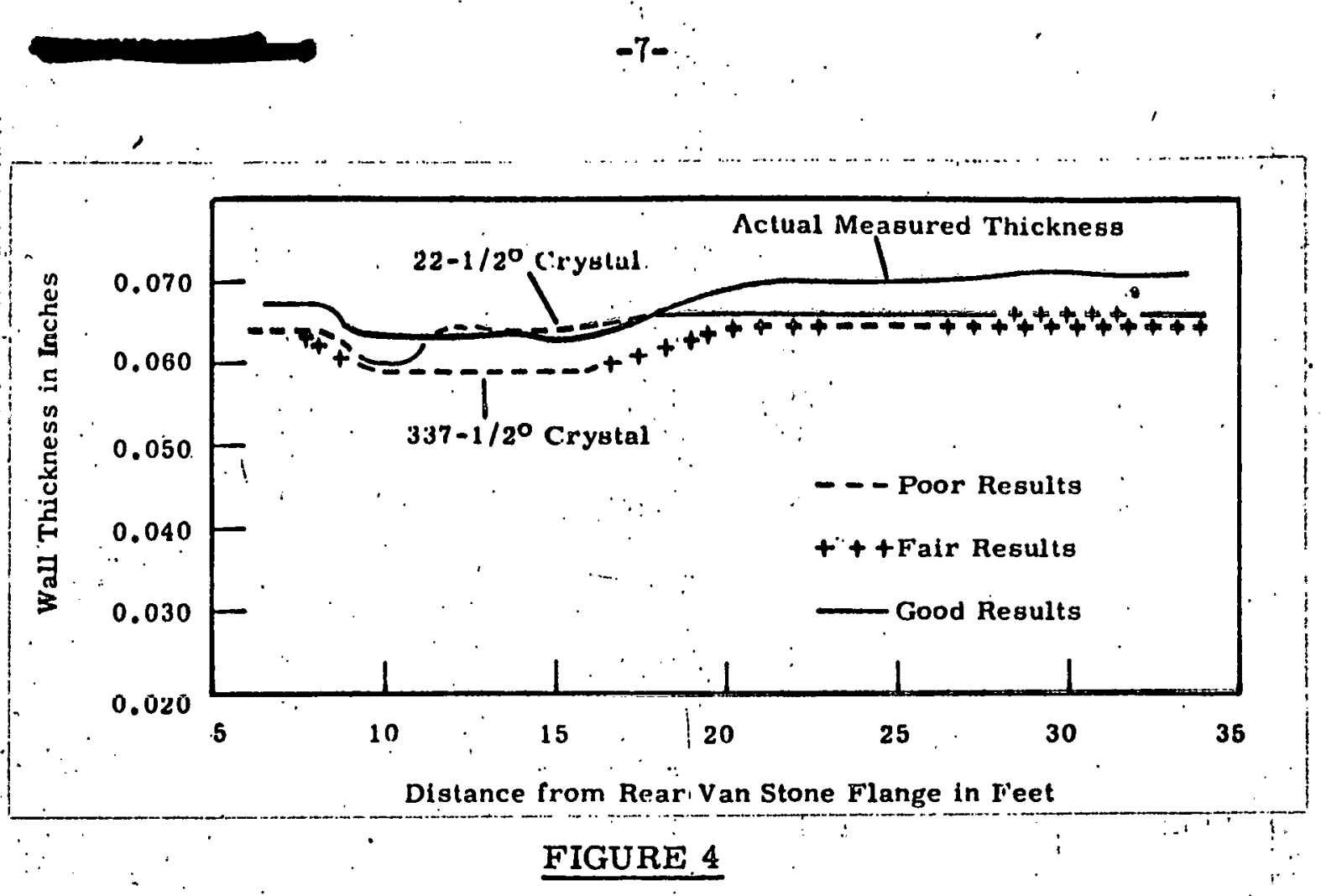

Thickness Profile, Top - Tube No. 4583-D

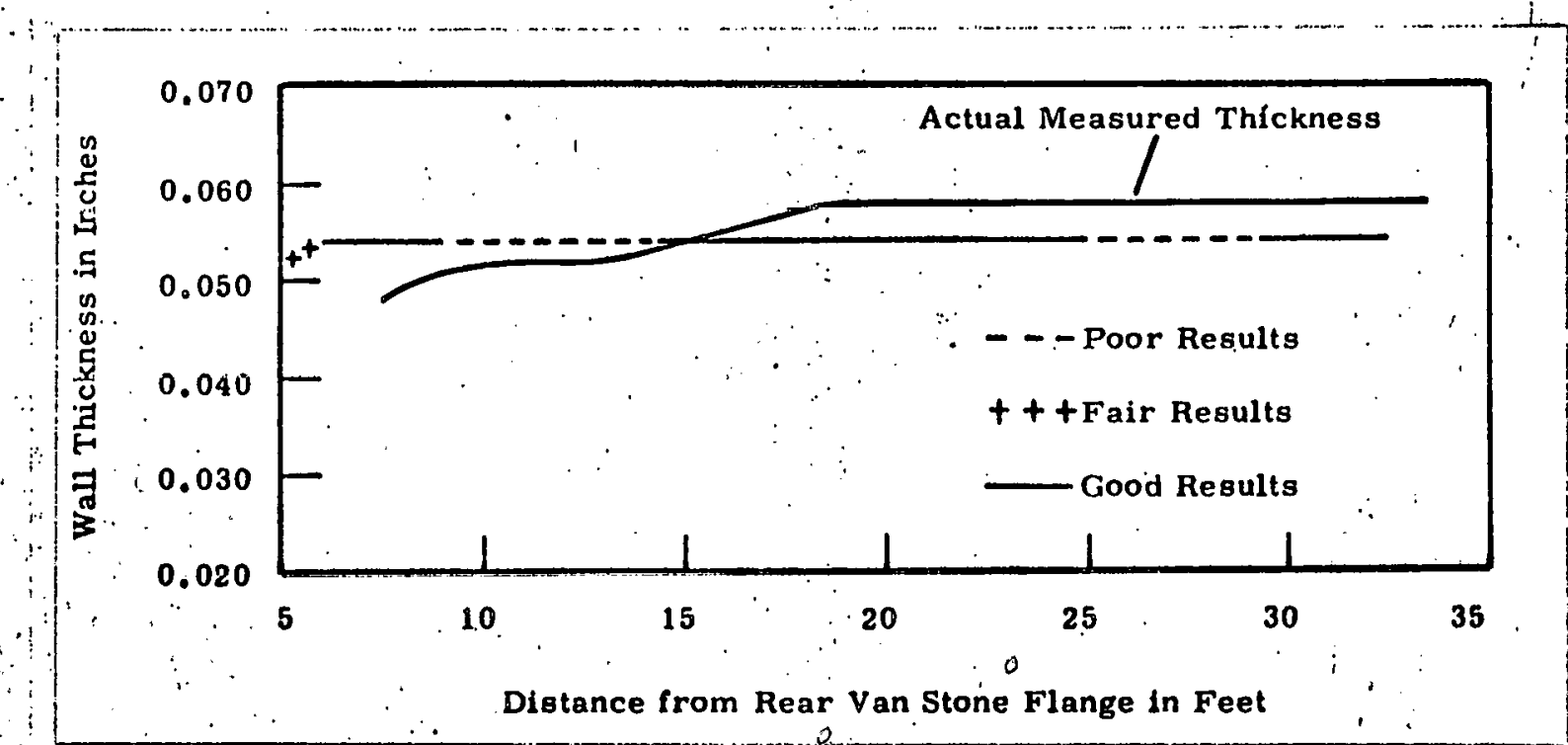

\section{FIGURE 5}

Thickness Profile, Bottom - Tube No 4583-D 


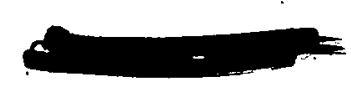

$-8 \div$ 0

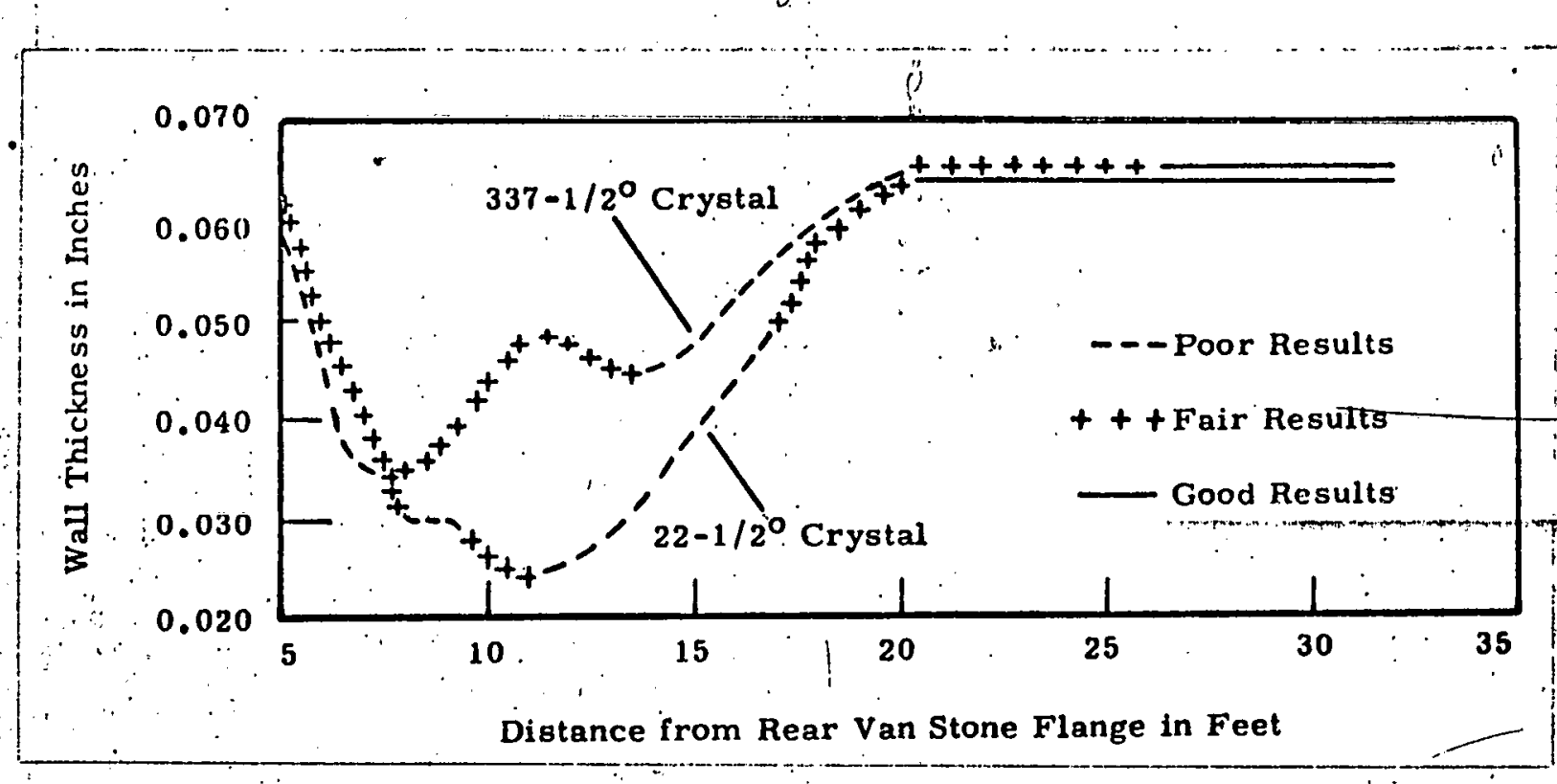

FIGURE 6

Thickness Profile, Top - Tube No. 1485-D

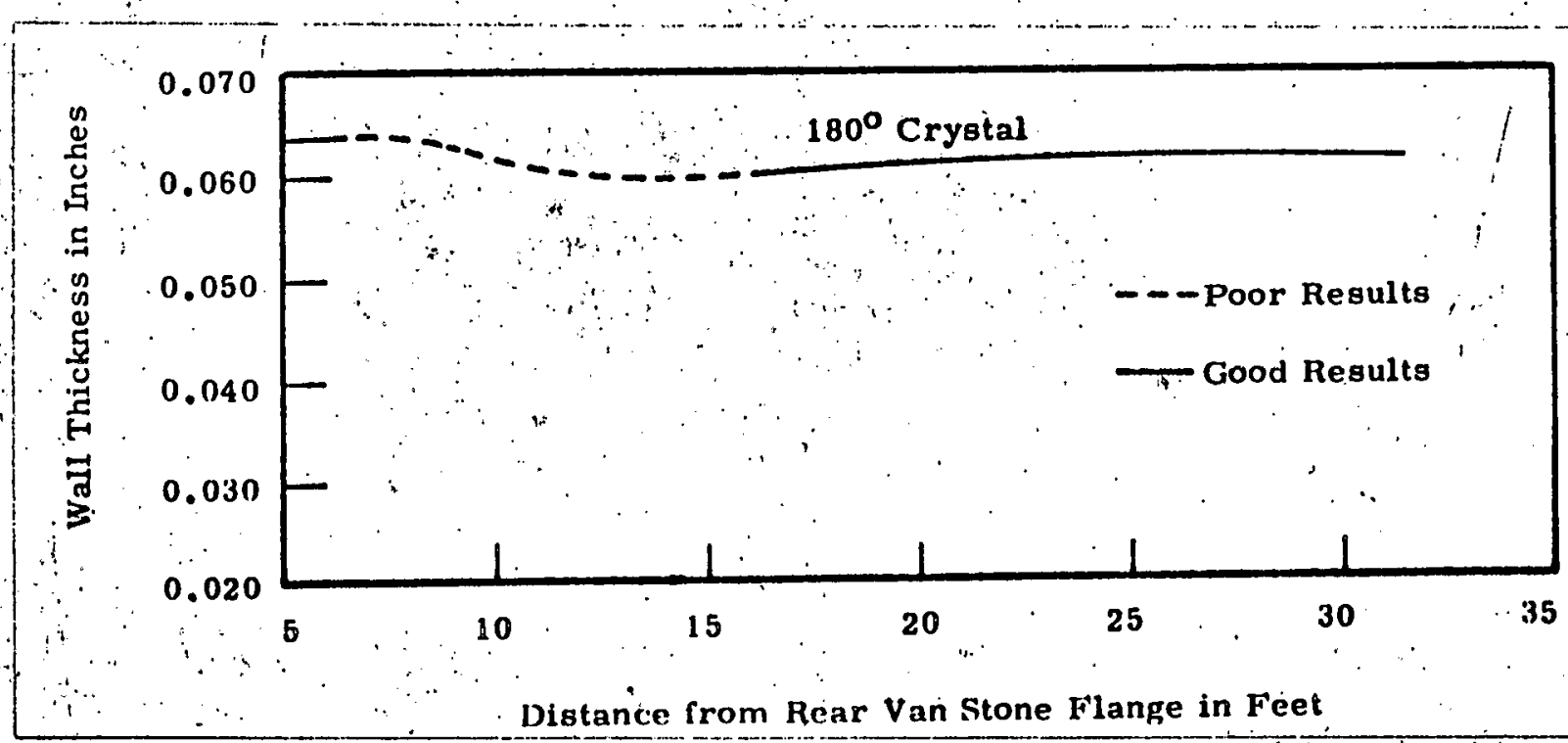

FIGURE 7 .

Thickness Profile, Bottom - Tube No, 1485-D 


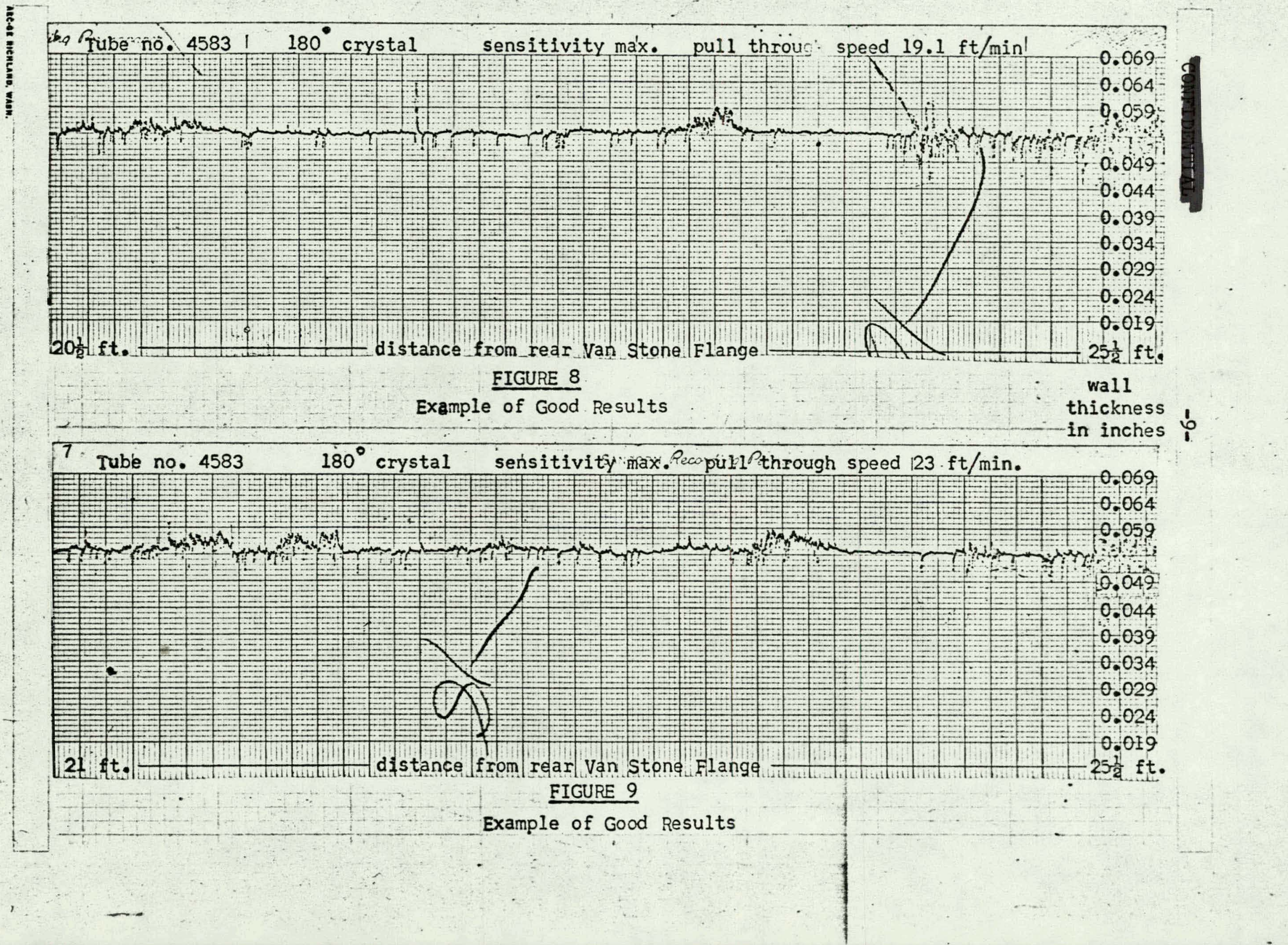




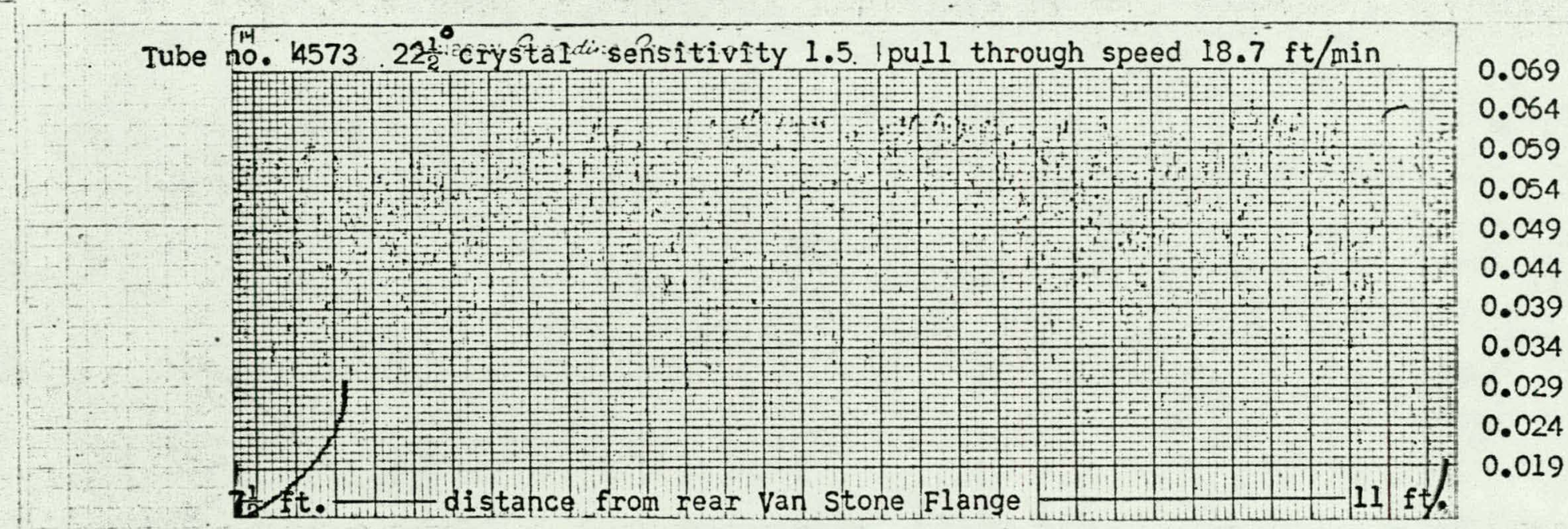

\section{FIGURE 10}

Example of Poor Results

wall

thickness

in inches
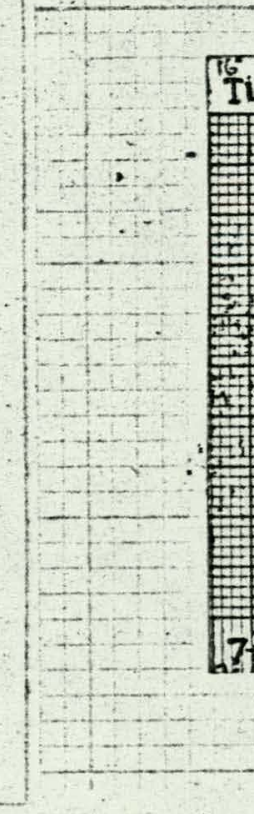

Thube no. 54573 A $180^{\circ}$ ircrystal oer sensitlvity $7.5^{\prime}$ pull through speed $18.2 \mathrm{ft} / \mathrm{min}$.

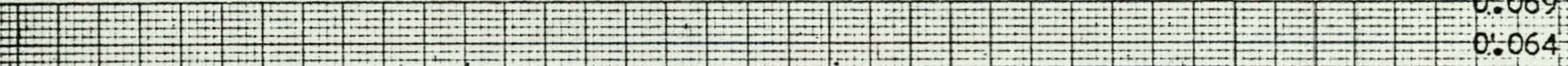

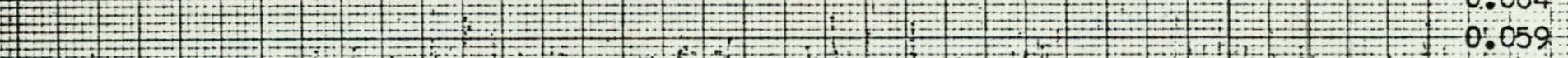

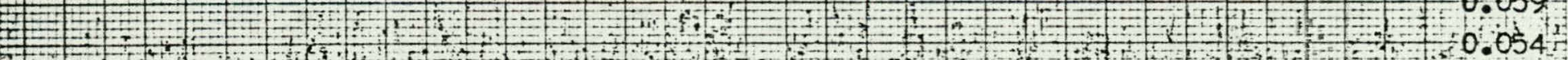

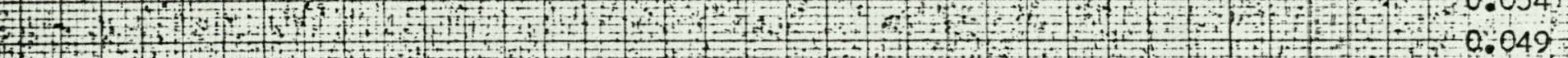

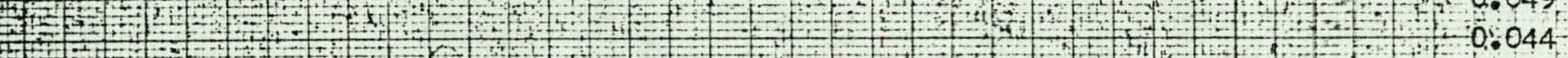

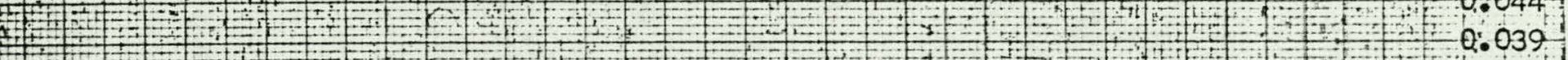

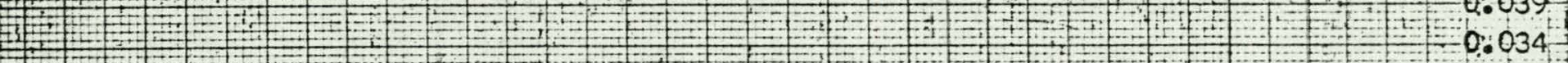

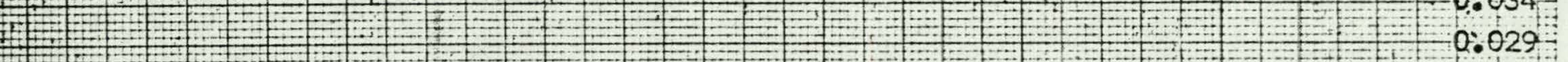
2. 4000.019 FIGURE 11

Example of Poor Results 

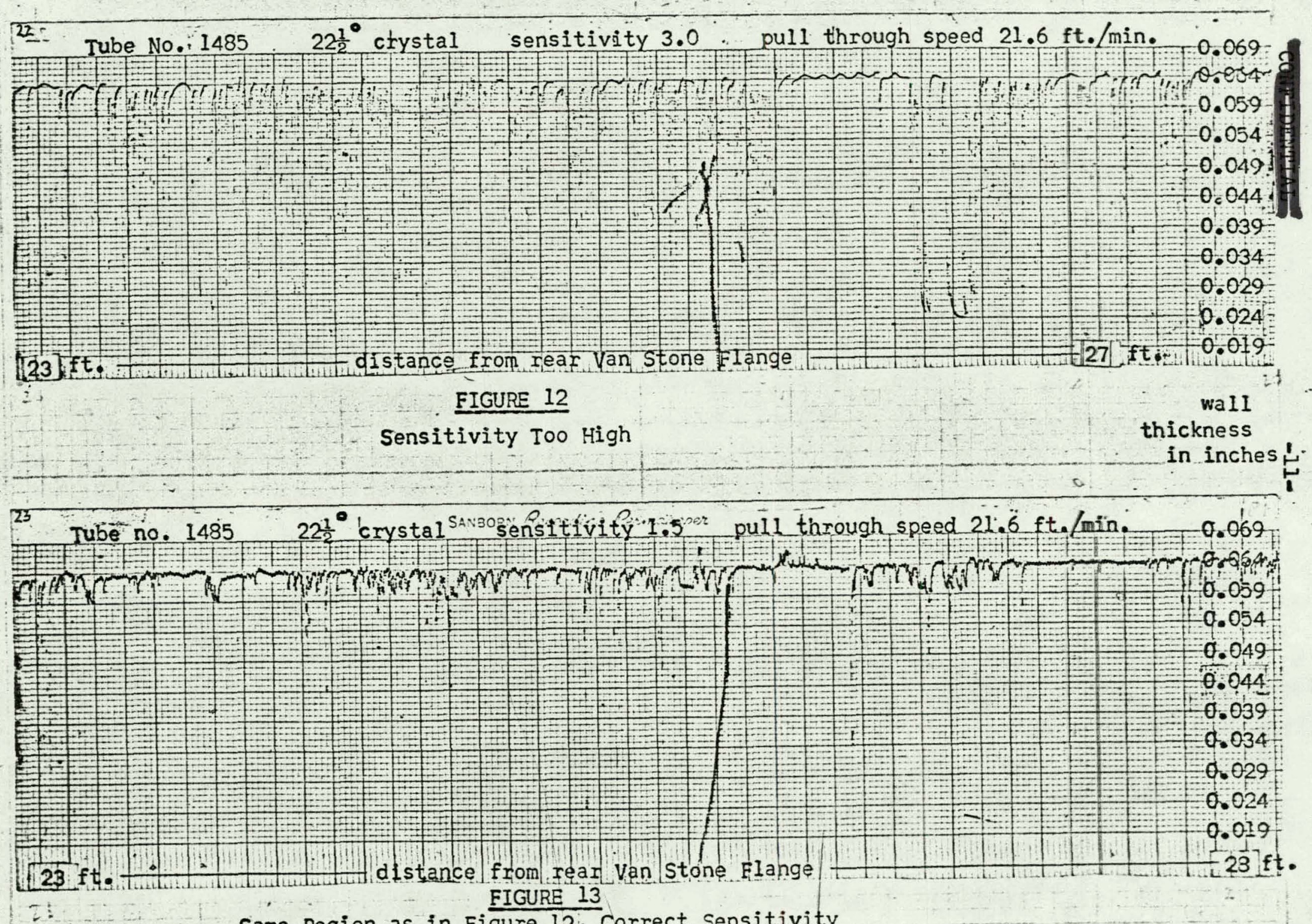

I:

Same Region as in Figure 12 , Correct Sensitivity

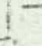

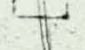




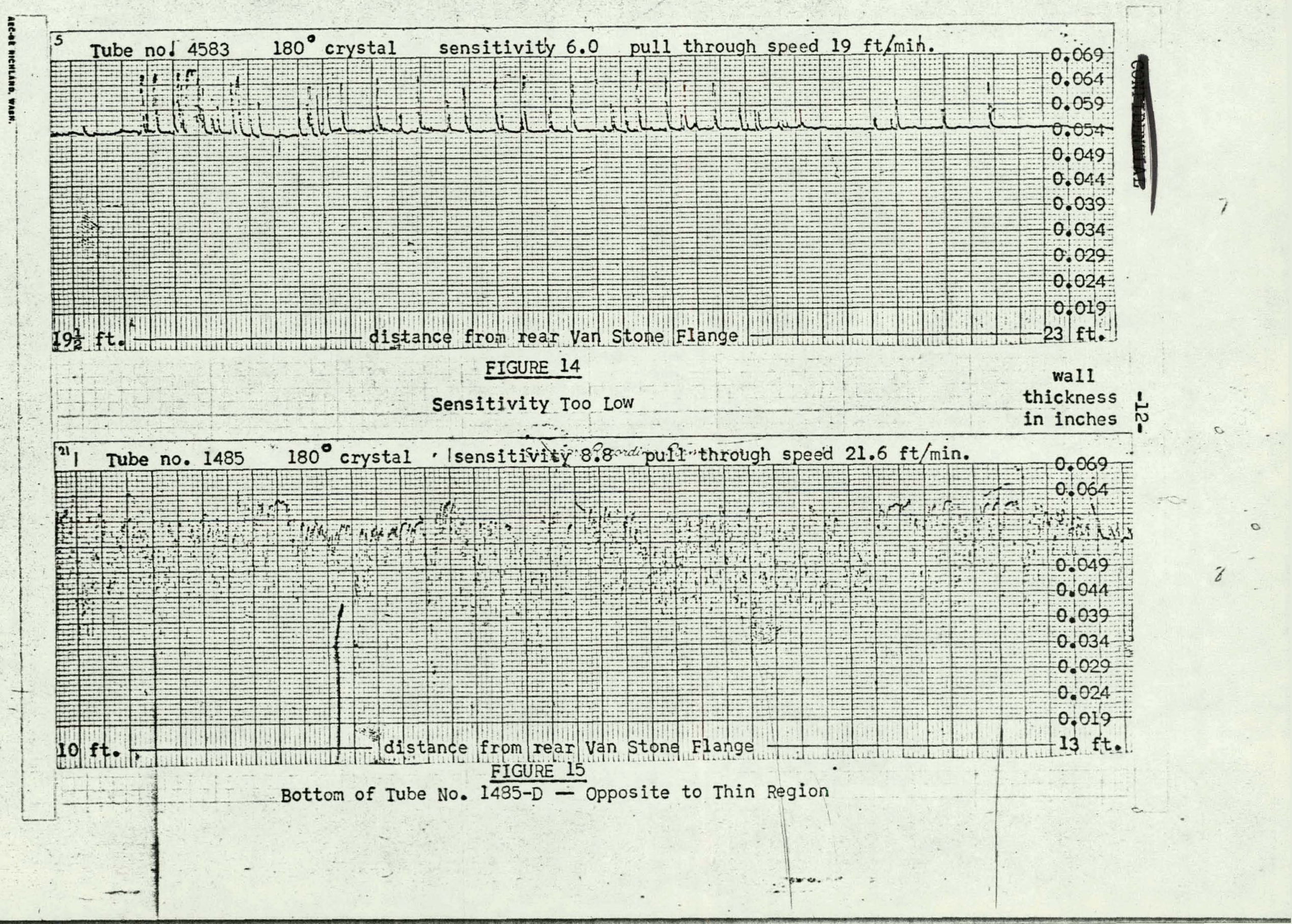




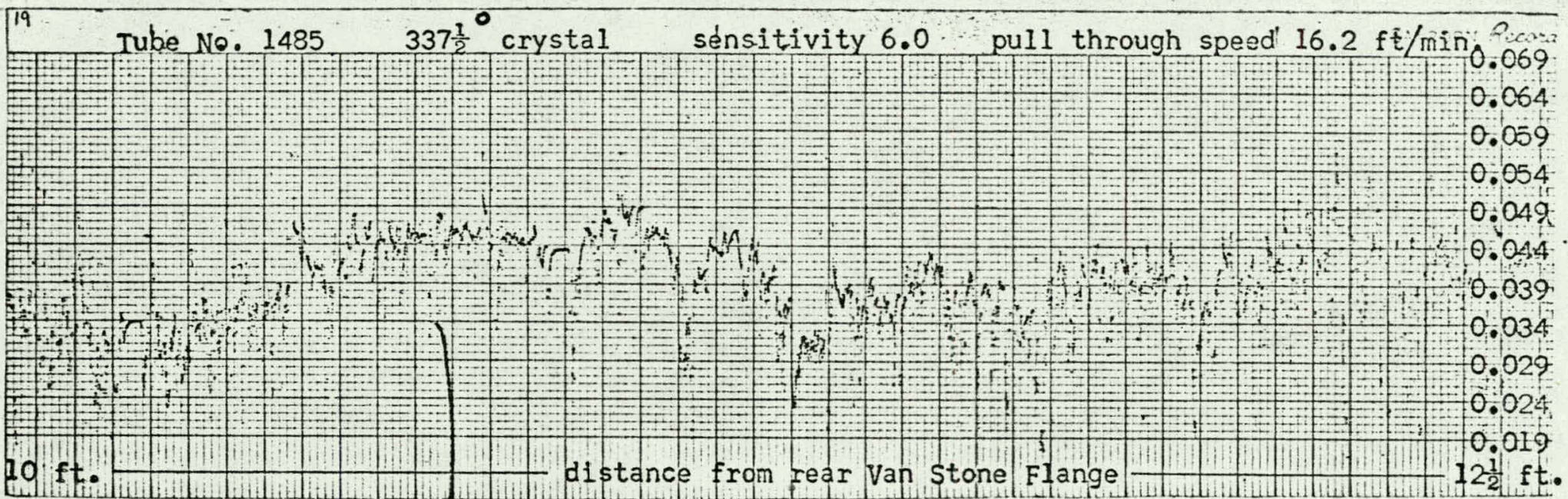

\section{FIGURE 16}

wall

Thin Region, Top of Tube No. 1485-D

thickness

in inches

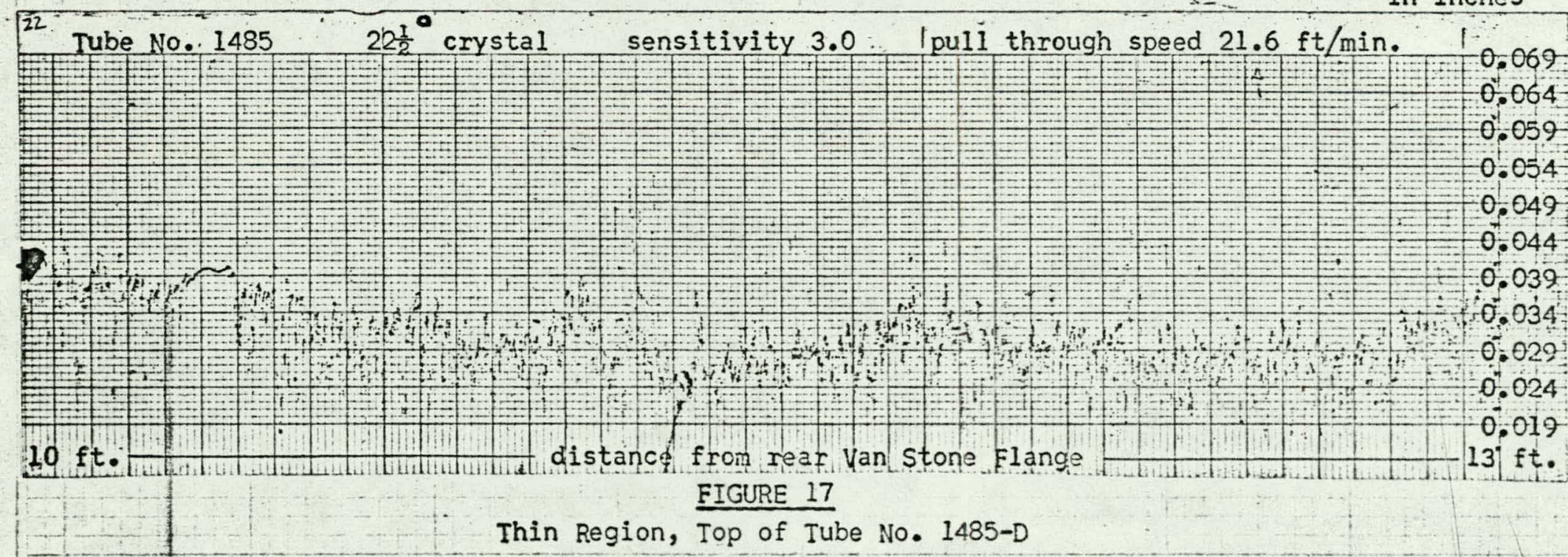


not removed from the reactor, are shown in Figures 15, 16, and 17. Figures 16 and 17 are examples of fair results with some poor results regions. EXAMINATION OF PIECES FROM REMOVED TUBE

\section{A. Procedure}

The cause of poor echoes from large portions of the three tubes involved in the in-reactor trial was thought to be closely spaced corrosion pits and/or film. Two tubes, \#4573 and \#4583, were removed and partly cut into small pieces for micrometer measurement. Four heavily filmed top and bottom pieces were selected from poor echo regions of tube $\# 4573$ for additional ultrasonic examination. Original locations of these pieces were at $10 \mathrm{ft} 9 \mathrm{in}$, and at $7 \mathrm{ft} 9 \mathrm{in.}$ from the rear Van Stone flange. Each piece was examined at a number of regions using a crystal identical to those used in the in-reactor trial. Film was then removed and the examination of each piece repeated at the same amplifier sensitivity setting as used before film was removed. See Figures 19 through 26 for photos of the four pieces before and after film removal. Manipulating equipment was such, as to prevent re-examination of the precise regions examined before film removal. Nevertheless, there was a degree of uniformity on each piece permitting an evaluation of the general effects of film and corrosion.

\section{B. Results}

Lighter colored film apparently causes less signal distortion than does darker colored film. Clean echo waveforms were common on light film areas, but practically nonexistent on dark film areas. See Figures 27 and 34 for examples of echoes from light film areas. Time base on photos of Figures 27 through 46 is 200 nanoseconds per large division. 


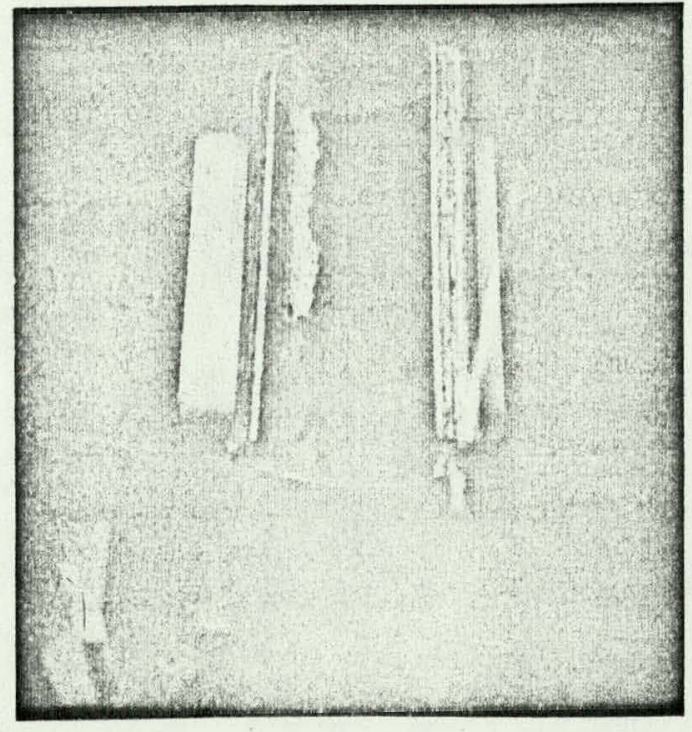

FIGURE 19

$7^{\prime} 9^{\prime \prime}$ Top

Before Film Removal

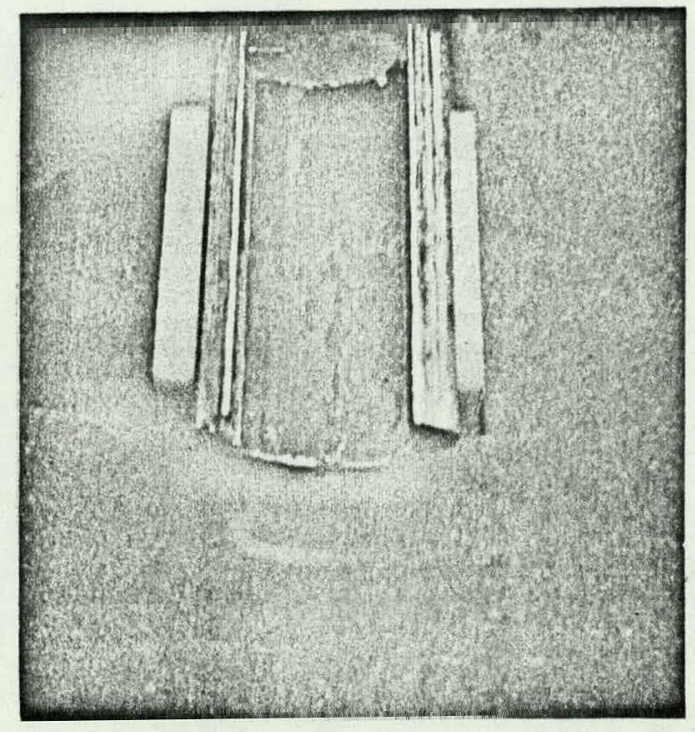

FIGURE 21

$7^{\prime} 9^{\prime \prime}$ Bottom

Before Film Removal
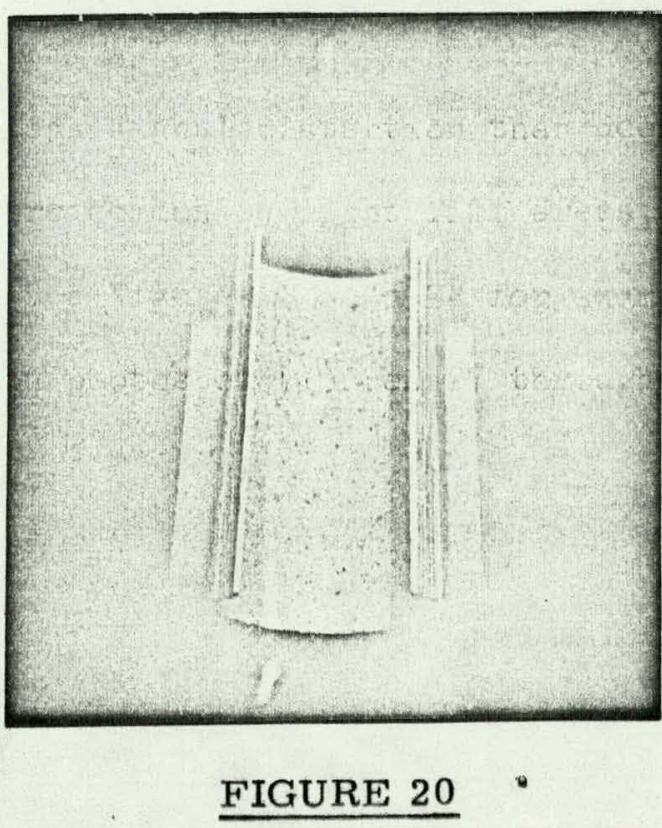

7'9" Top After Film Removal

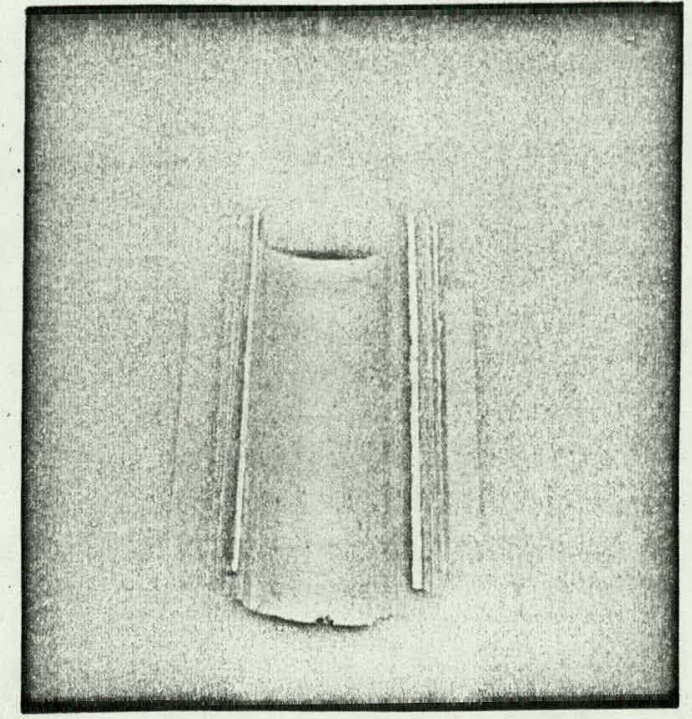

FIGURE 22

7'9" Bottom After Film Removal 


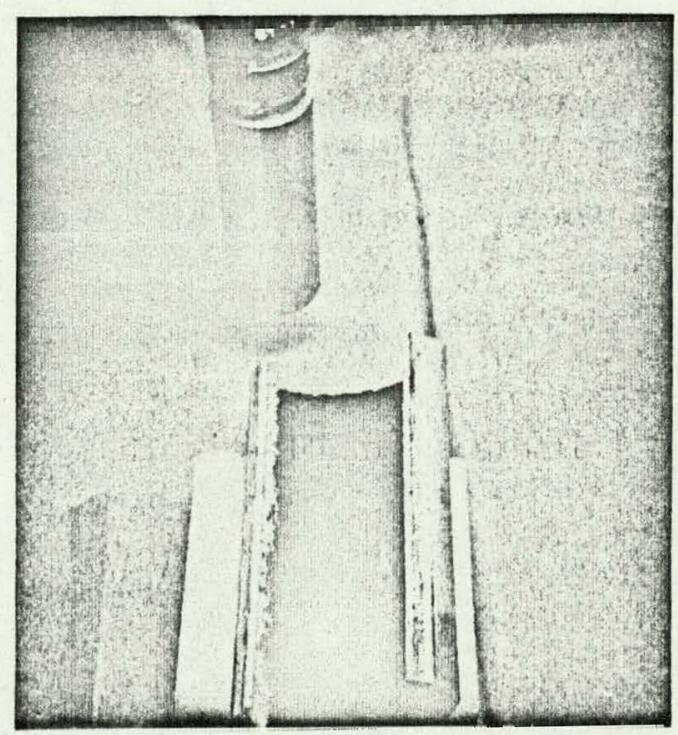

FIGURE 23

10'9" Top

Before Film Removal

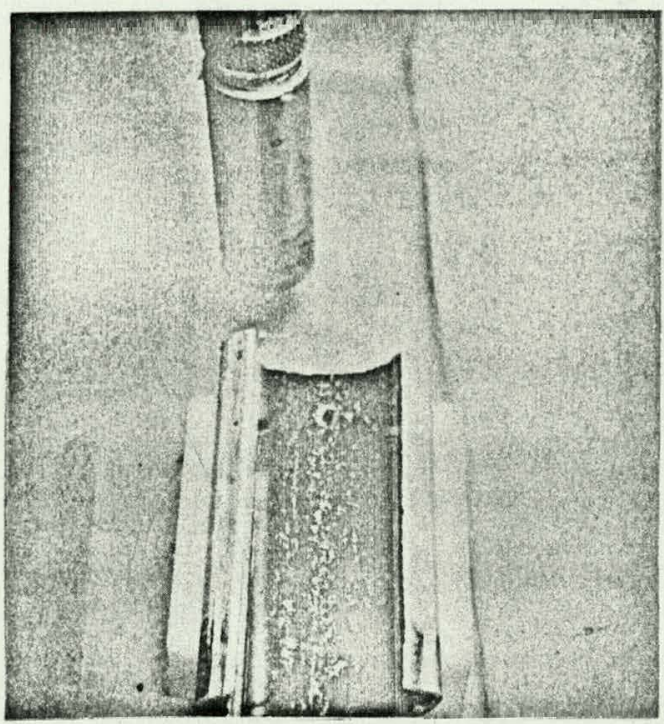

FIGURE 25

$10^{\prime} 9^{\prime \prime}$ Bottom

Before Film Removal

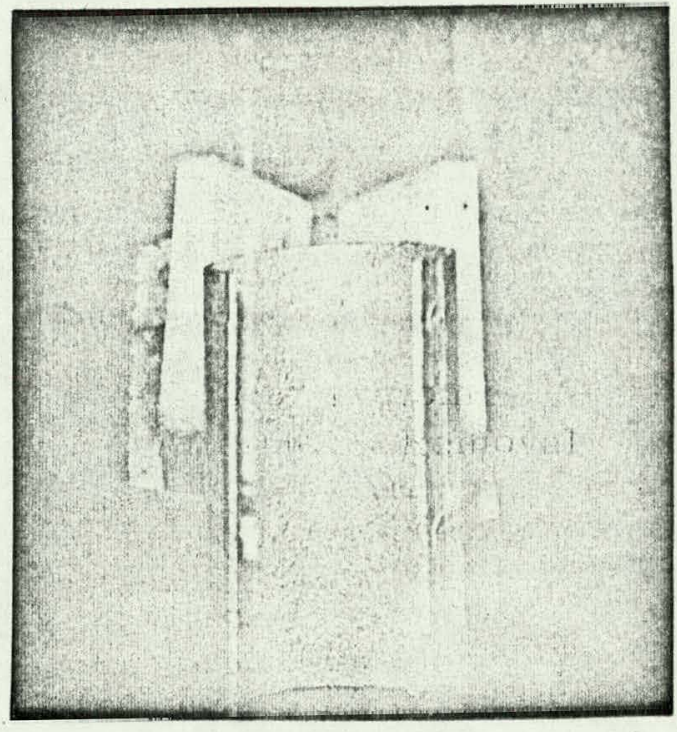

FIGURE 24

$10^{\prime} 9^{\prime \prime}$ Top After Film Removal

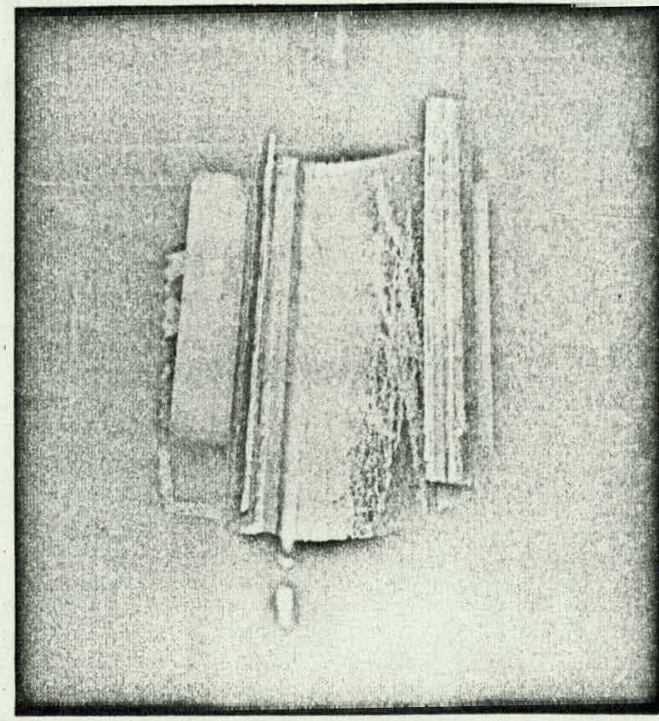

FIGURE 26

$10^{\prime} 9^{\prime \prime}$ Bottom After Film Removal 
$-17-$

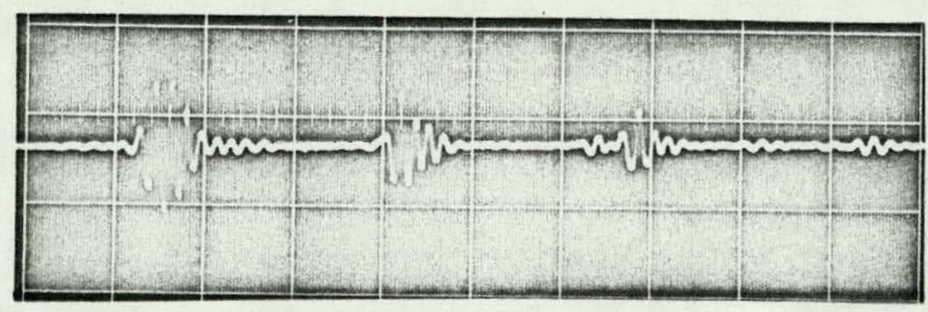

FIGURE 27

$7^{\prime} 9^{\prime \prime}$ Top, Light Film, Good Echoes

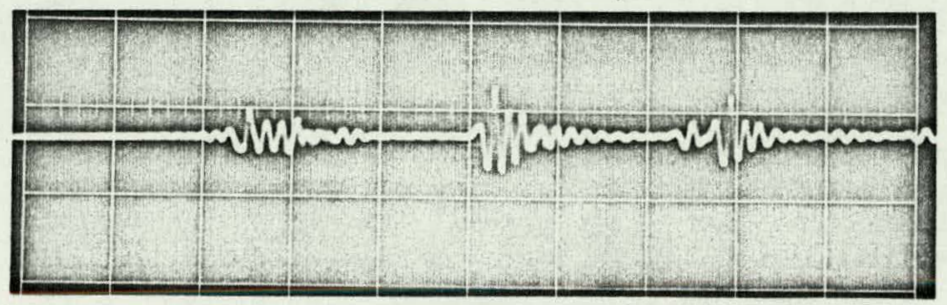

FIGURE 28

7'g" Top, Dark Film, Two Part Front Surface Echo

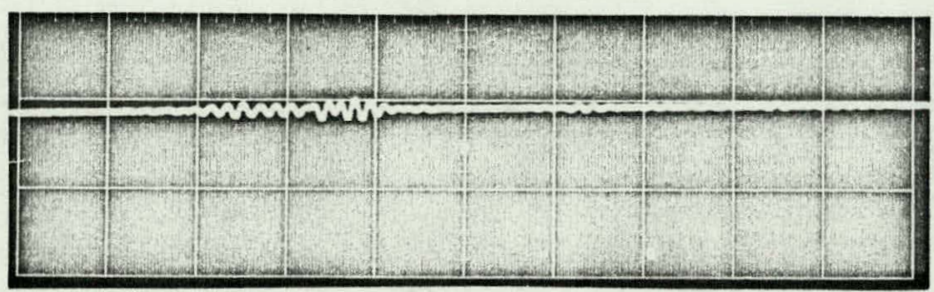

FIGURE 29

$7 ' 9^{\prime \prime}$ Top, Dark Film, Loss of All Echoes

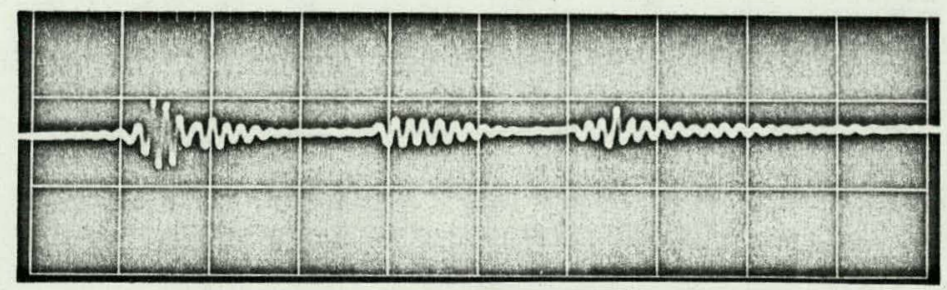

FIGURE 30.

7'9" Top, Dark Film, Loss of First Back Surface Echo 


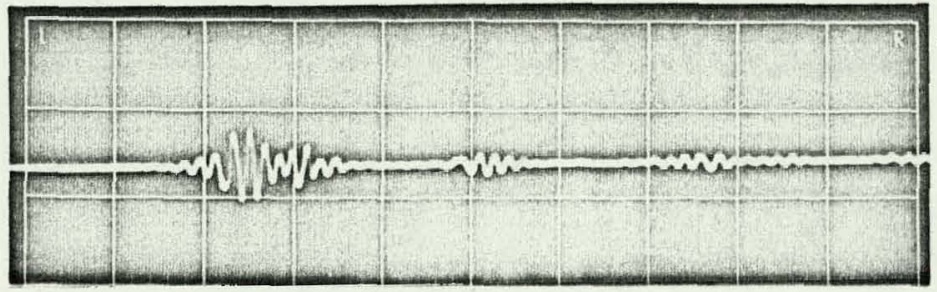

\section{FIGURE 31}

7'9' Top, Dark Film,Loss of all Back Surface Echoes

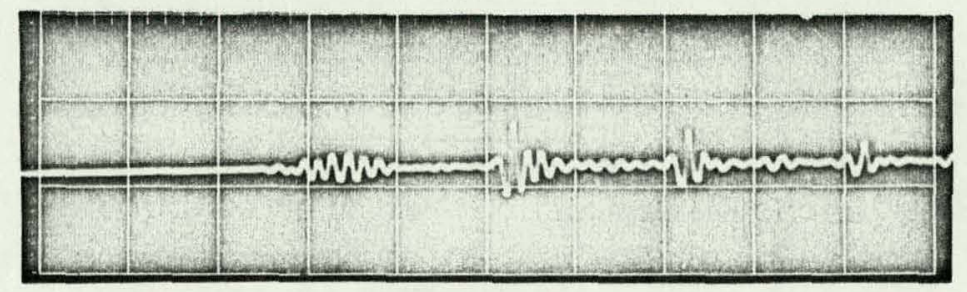

FIGURE 32

$10^{\prime} 9^{\prime \prime}$ Bottom, Dark Film, Loss of Front Surface Echo

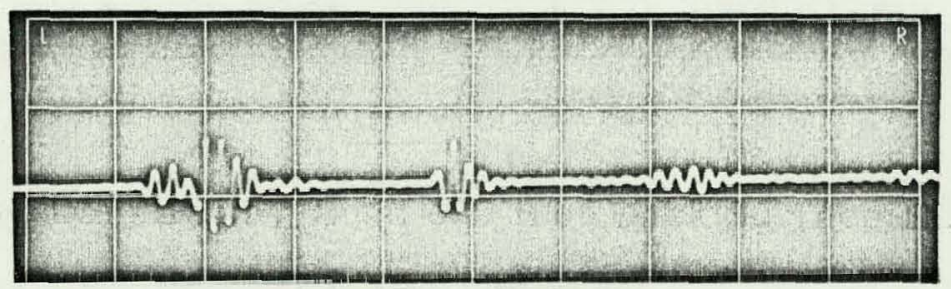

FIGURE 33

7'9' Top, Edge of Dark Film Area, Two Part Front Surface Echo

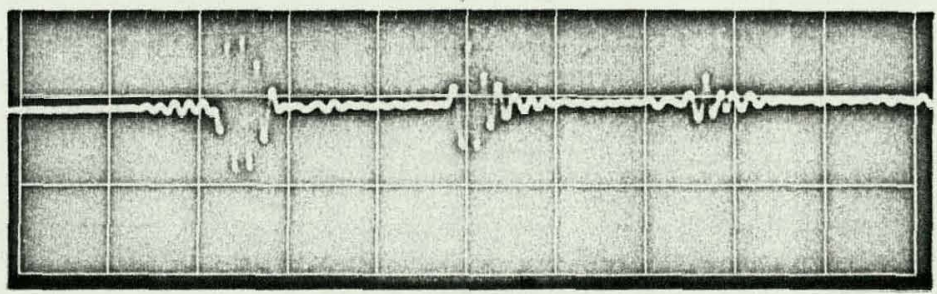

FIGURE 34

$7^{\prime} 9^{\prime \prime}$ Top, Light Film, Typical 


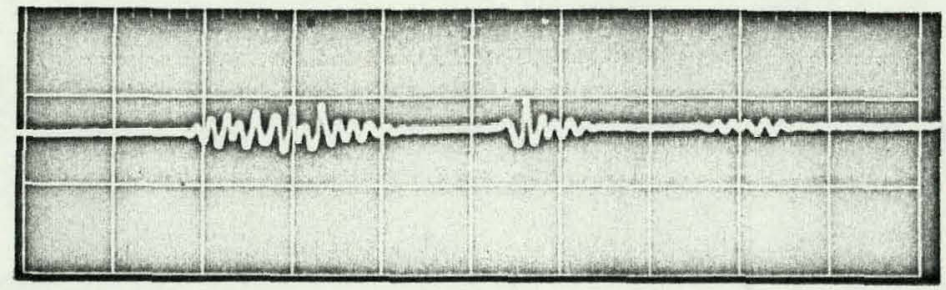

FIGURE 35

$7^{\prime} 9^{\prime \prime}$ Top, Dark Film, Typical

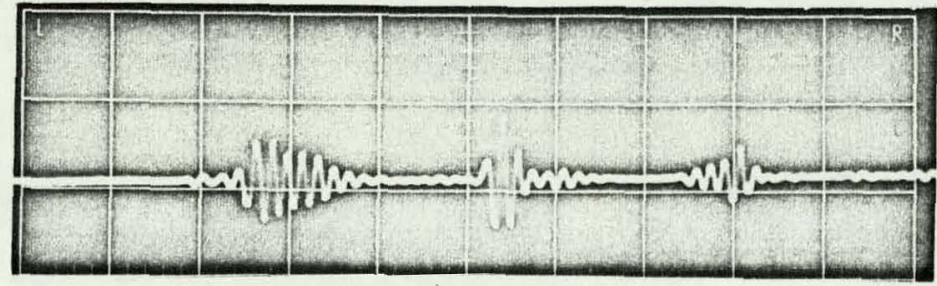

FIGURE 36

$7 ' 9^{\prime \prime}$ Top, Light Film, Immediately Adjacent to Area of Figure 35

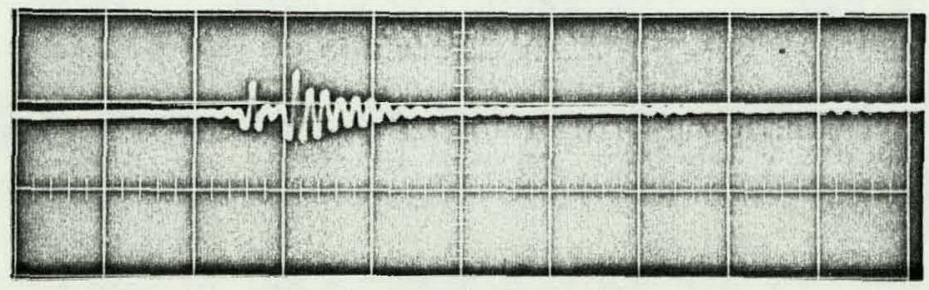

FIGURE 37

7'9" Bottom, Dark Film, Typical

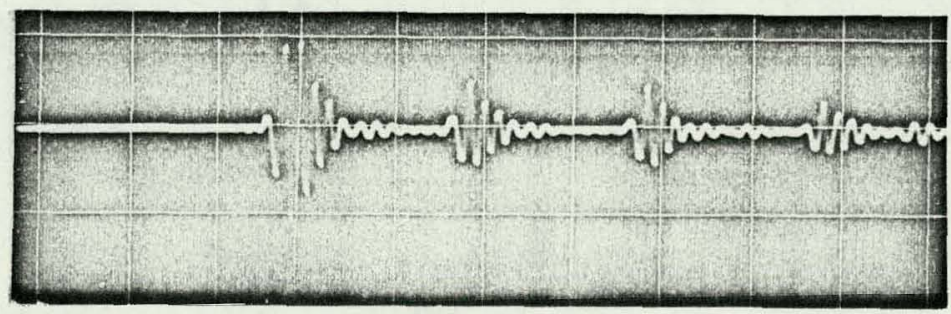

FIGURE 38

$7 ' 9^{\prime \prime}$ Bottom, No Film, as Close as Possible to Area of Figure 37 


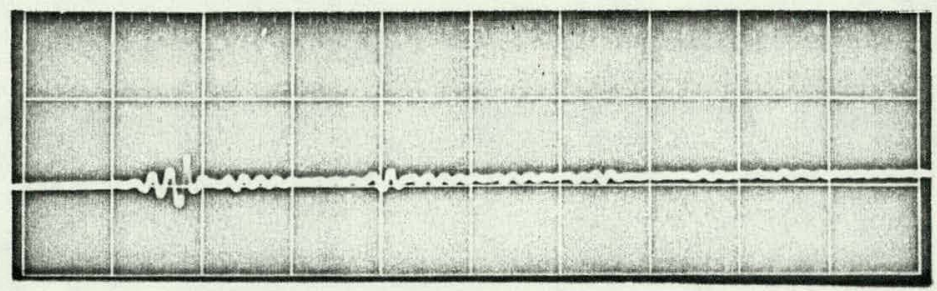

FIGURE 39

10'9" Top, Film Removed, Typical

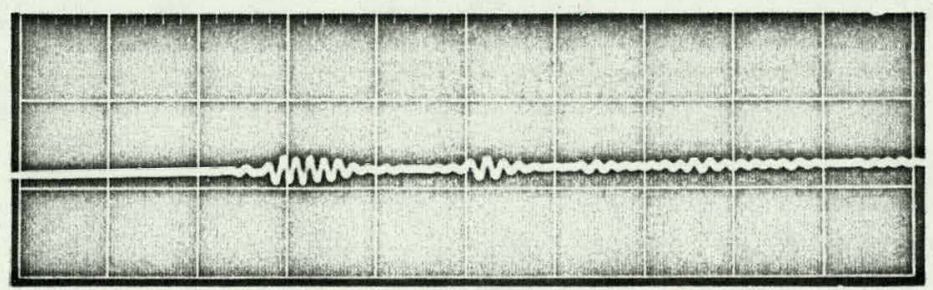

FIGURE 40

7'9' Top, Film Removed, Typical

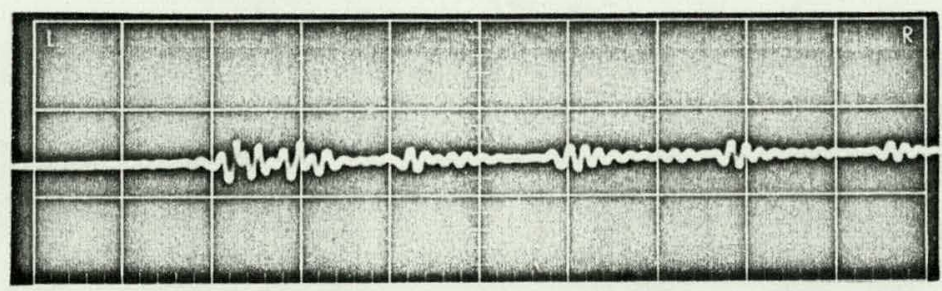

\section{FIGURE 41}

10'9" Bottom, Film Removed, Two-Part Front Surface Echo

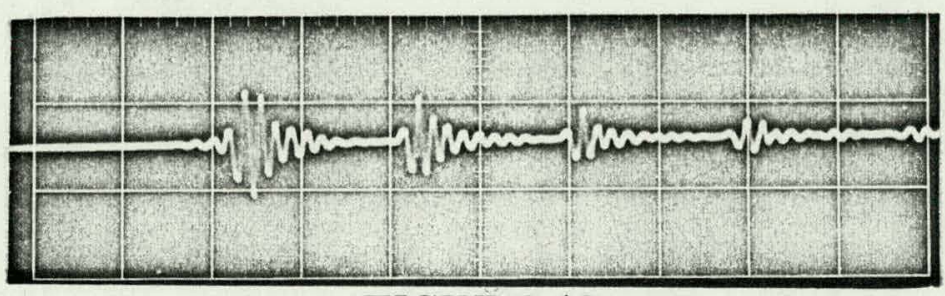

FIGURE 42

$10^{\prime} 9^{\prime \prime}$ Bottom, Film Removed, Good Echoes Immediately Adjacent to Area of Figure 41 


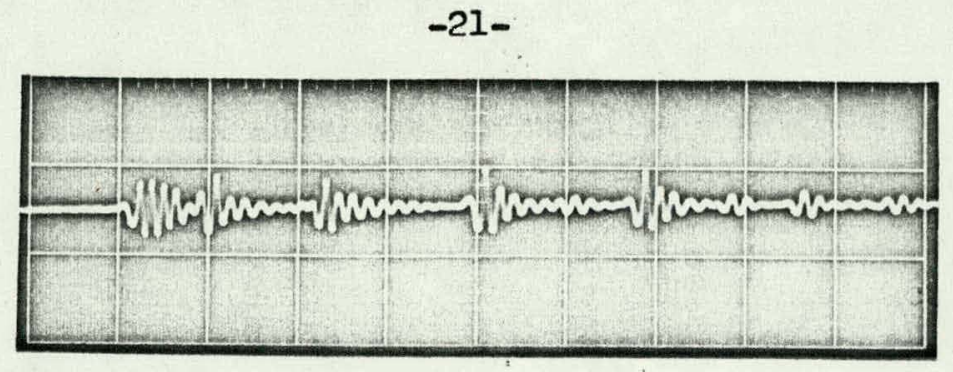

FIGURE 43

$10^{4} 9^{\prime \prime}$ Bottom, Film Removed, Two Part Front Surface Echo

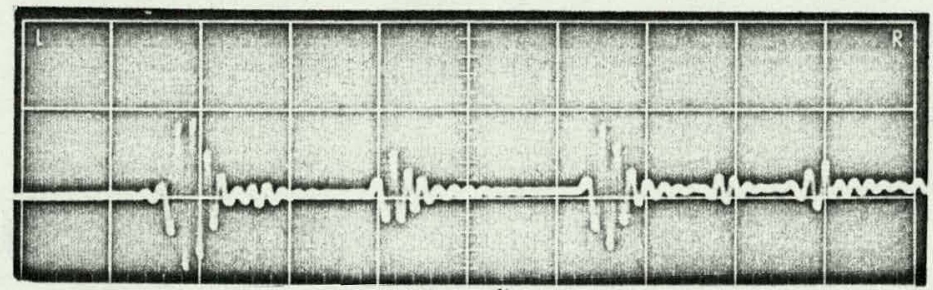

FIGURE 44

0.065 in. Standard

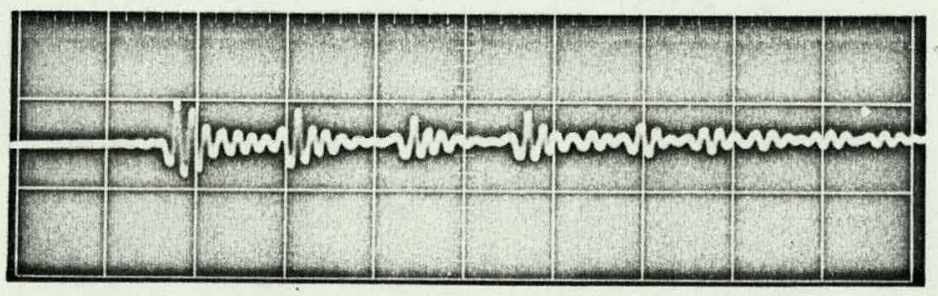

FIGURE 45

0.035 in. Standard (Etched Surface)

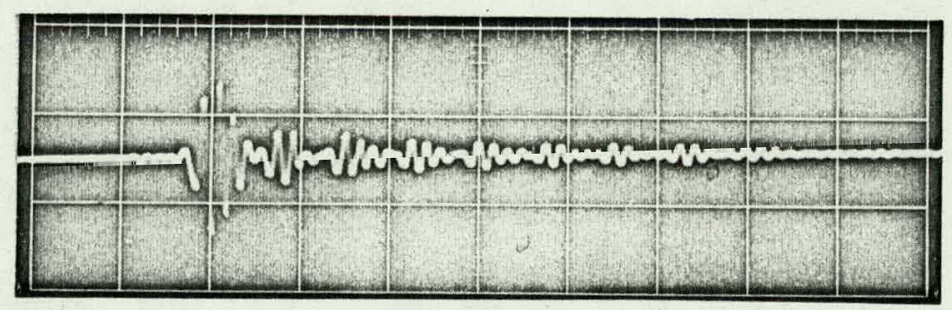

FIGURE 46

0.021 in. Standard 
All known signal distorting situations were found on the film covered samples:

1. Multiple peaked front surface echo. which causes a false reading in the thin direction (See Figure 28).

2. Loss of all echoes -- which causes a false reading in the thin direction (See Figure 29).

3. Loss of first back surface echo - which causes a false reading in the thick direction (See Figure 30).

4. Loss of back surface echoes -- which causes a false reading in the thick direction (See Figure 31 ).

5. Loss of front surface echo but presence of subsequent reverberations -- which generally results in near correct readings (See Figure 32).

Signal distorting situations occur in about half the area; most frequent situations were Nos. 1,2 , and 4 .

Further indications of film properties are seen in Figure 33. The crystal was maneuvered to the edge of a dark $112 \mathrm{~m}$ area. The two-part surface echo indicates dark film thickness of about $0,003 \mathrm{in}$. greater than adjacent area. Film thickness of the adjacent area cannot be determined from Figure 33. A typical echo from dark film is seen in Figure 35. A light film echo from an area close to that of Figure 35 is shown in Figure 36. Note that signal waveform is less distorted over light film than over dark film.

Little corrosion was present on the $7 \mathrm{ft} 9$ in. bottom sample. Echoes. from this sample were substantially better with film removed than with film present. For example, Figure 38 shows the improved waveform obtained at the approximately same location as Figure 37 after flim has been removed. Etch type corrosion was present on both top samples. Echoes from light f1lm 
regions of these samples generally became worse after film was removed. See Figures 39 and 40 for examples.

Corrosion areas in the $10 \mathrm{ft} 9 \mathrm{in}$. bottom sample were more widely spaced compared to the top pieces. Echoes from this piece were about the same with or without film - sometimes good, sometimes bad. See Figures 41, 42, and 43. A two-part surface echo has resulted from the rough corroded surface. as seen In Figure 43.

Thickness readings were slightly greater before film removal than after film removal. This and the multiple peaked surface echös at the edges of dark film substantiate the premise that film will cause a false reading. It was noted also, with film present, that time between front surface and back surfaces echoes' leading edges was greater than the time between first: and second back surface echoes. With film removed, these times were the same.

Echo waveforms from micrometer measured standards are shown in Figures 44. 45, and 46.

\section{DISCUSSION}

Considerable interpretation of test results was found to be necessary to establish estimated thickness readings. A high level of recorder fluctuation was responsible for lack of readily definitive recordings. Recorder fluctuation was caused primarily by a rough inner surface due to film and corrosion. The predominant effect on echoes from the rough surface was to cause a multipeaked front surface echo. If spacing between peaks was great enough, the instrument would interpret the peaks as front and back surface echoes and a false reading would result. (A discussion of instrument operation is found in the Appendix under Principle of Operation, page 11.) These false readings will be on the thin side of actual thickness with probably a large proportion at the minimum limt setting of $0.019 \mathrm{in}$. 
See Figure 47 for an illustration of the effects of rough surface. If wall thickness is $0.060 \mathrm{in}$. with no roughness, time between front and back surface echoes is $0.48 \mathrm{\mu sec}$. With a wall thickness of $0.025 \mathrm{in}$. echo time. spacing will be $0.20 \mathrm{\mu sec}$. If a surface depression should intercept a portion of the ultrasonic beam, a multipeaked surface echo will result. In Figure 47, time spacing between front surface echo peaks 1s 0.205 usec as a result of a 0.006 in. deep corrosion pit. A false reading of about 0.025 in. wall thickness will occur whereas minimum thickness is actually 0.054 in. If echo $b^{\prime}$ blended into echo $a^{\prime}$ so that a single wide front surface echo was returned, the readout would be 0.060 in.. rather than 0.025 in. or 0.054 in. since the readout circuitry will operate on the leading edges of the surface echoes.

Beam diameter of crystals used in this project was about $0.060 \mathrm{in}$. to $0.080 \mathrm{in.} \mathrm{-}$ too large to fit within most individual pits and thereby reduce multipeaked surface echoes. Smaller diameter beams are possible but not recommended due to expected excessive beam scatter.

Time did not permit determination of the elastic properties of corrosion product film, but ultrasonic examination of the four cut pieces proved that film is not transparent to ultrasound. The extent of reflection at a film interface will be dependent on its characteristic impedance, $z_{0}$. If film's $z_{0}$ is considerably less than that of aluminum but considerably more than that of water, as thought to be, then echoes will occur at the water-film interface and at the film-aluminum interface. Echo amplitude at both Interfaces; however, will be less than that from a water-aluminum interface. The longltudinal velocity of film is thought to be about that of water $(58,500 \mathrm{in.} / \mathrm{sec})$. With such a slow velocity, the effect of f1lmi on measurement accuracy would be 


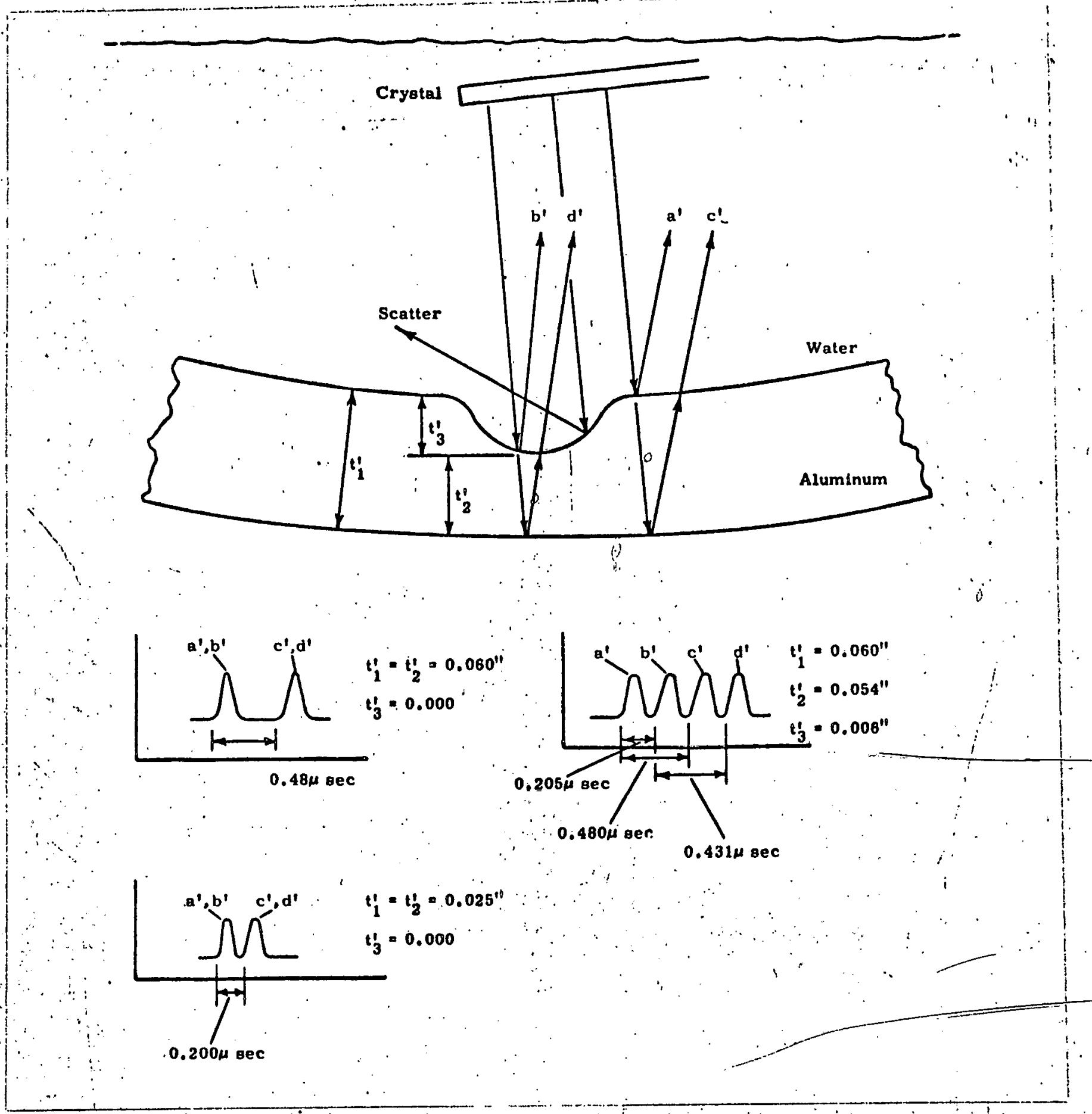

FIGURE 47

Ultrasonic Reverberation Patterns in Aluminum with and Without Corrosion Pit 
appreciable since the first echo components of the front surface echo will be from the water-film interface. The probable effect of film is illustrated in Figure 48. Echoes from the film-aluminum interface will confuse the readout circuitry。

Accuracy will 1mprove with thinning film as the fllm-aluminum echoes will die out before the back surface echo arrives. The problem of multipeaked front surface echoes, as caused by rough film and significant echoes from the film-aluminum interface, will still cause measurement error. Accuracy will be improved by utilizing the back surface echoes -- echoes $d$ and $h$ in figure 48 - since they do not include error due to film thickness $t_{1}$. RECOMMENDATIONS

A number of instrumentation improvements may be made to improve readout. Inasmuch as undistorted echoes appeared no less than at least once per half inch of longitudinal travel, a basis exists for thickness measurement of half inch increments. A problem of discriminating between actual thinning and false indicated thinning can be reduced by increasing the measurement syotem's amplifier response time constant; this would have the effect of blending together the multiple peaks of a front surface echo. Such would be accomplished at the expense of resolution. For example, minimum thickness resolution might become 0.030 to 0.040 inch in order to eliminate a significant amount of multiple peaking.

Further improvement can be made by modifying the readout circuitry and using a faster responding recorder. Since most distorted echo situations result 


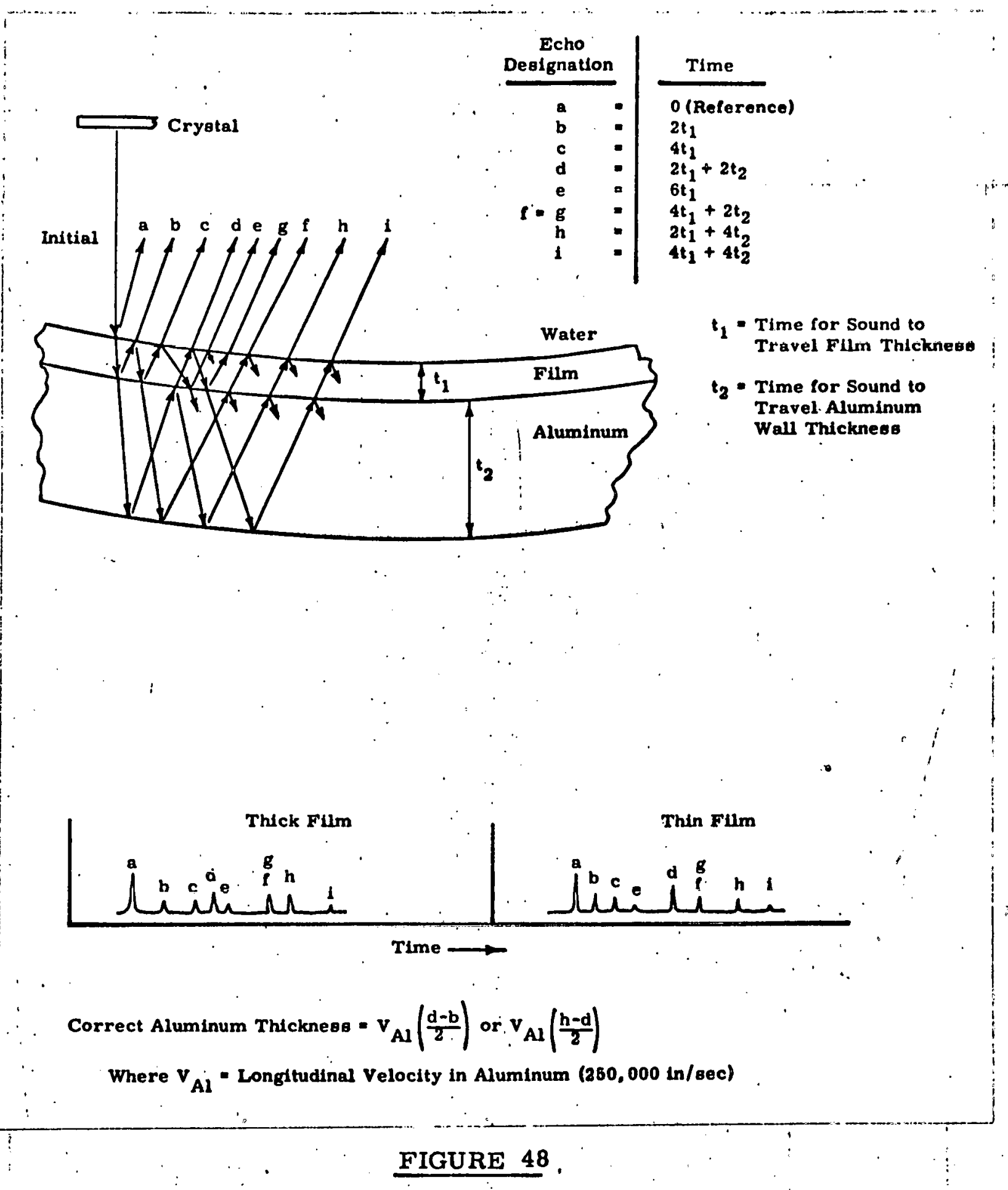

Ultrasonic Reveration Patterns (Simple) in Film Covered Aluminum 
in recorder fluctuations in the thin direction, a longer time constant should $\because$ be imposed in the thin direction. A fast recorder, such as a light r.ugalvanometer recorder, would respond at the slow driving rate of the ultrasonic instrument's readout circuitry -- in the thin direction -- but would return very quickly to the correct thickness reading. An undesirable effect of such changes would be to increase the minimum length of a corrosion thinned area that may be detected. For example, minimum length 0 as established by recorder transient response time, could be increased to about one inch.

Multiplexing of a multiple crystal array and corresponding amplifier, readout, and other circuitry, while technically feasible, is judged to be too" complex and potentially troublesome for use in an in-reactor eavironment. If simultaneous measurement of both top and bottom are desired, multiple instrumentation would be preferred. Some circuit functions need not be duplicated and packaging for a two or three sector test instrument would not be difficult. Other techniques - not recommended at this time -- could improve readout accuracy. Some of these techniques are: (1) one-inch interval recycling multichannel pulse height analysis of the readout thickness analog waveform which would show a large percentage of total count at one thickness -- presumably the correct thickness, (2) gating on the first two back surface echoes rather than on the first front surface echo and the first back surface echo; or develop a dual gating concept whereby the better of two readings is selected for the recorded readout, and (3) logarithmic or automatic gain control. If no additional development is wanted at this time, considerable usefulness nevertheless would be obtained from using the instrument as-is with an operator readout for interpretation of the $R F$ pulse-echo waveforms on a monitoring oscilloscope. Inasmuch as a visual interpretation can only be made with the probe at rest, the operator interpretation technique would be most applicable in inspecting suspect regions located with the Probolog. 
REFERENCES

1. D. E. Strege, J. R. Young, Reactor Process Tube Damage, HW-68222, March I, 1961 。

2. J. Mo Fouts, The Probolog's Role in the Measurement of Reactor Process Tubes, HW-62124, December 28, 1961.

3. R. V. Dulin, A System for Measurement of Wall Thickness of Corroded Aluminum Reactor Process Tubes; HW-SA-3106, October 11, 1963 .

4. R. L. Brown Jr., Study of Feasibility of Aluminum Process Tube Wall Thickness Measurement; TM-MEMO-65-1, February 1, 1965. 


\section{APPENDIX}

\section{MEASUREMENT REQUIREMENTS}

Measurement requirements are defined in L. V. Barker's letter to

D. C. Worlton, dated October 9, 1964. They are summarlzed as follows:

1. The developed instrument shall be capable of making in-reactor measurements of (a) $90^{\circ}$ to $120^{\circ}$ top sector, and (b) the bottom sector between tube ribs (about $60^{\circ}$ ).

2. Minimum thickness resolution is 0.035 in.

3. Measurement error shall be no greater than $\pm 0.002 \mathrm{in}$.

4. Local corrosion areas such as $0.375 \mathrm{in}$. diam by $0.010 \mathrm{in}$. deep should be detectable.

5. Maximum length of measured sections should not exceed 1.0 in.

6. Measurements to be conducted top and bottom simultineously at a probe pull-through speed of 12 to $24 \mathrm{ft} / \mathrm{min}$.

Allowances were included for modification of requirementa according to operational needs and instrument characteriatics.

\section{LIST OF EQUIPMENT}

A. Leased Equipment

1. Sperry UMT21 Display and Timer Chassis

2. Sperry 50E568 TR Thickness Module

3. Automation Indistries 57C3815B Pulser Amplifier Module

B. Purchased Equipment

1. Three special transducers - $22 \mathrm{MHz}$ damped, spherically focused lithium sulphate

2. One special transducer - $22 \mathrm{MHz}$ damped wedge focused lithium sulphate

C. Laboratory Equipment

1. Tektronix 551 Oscilloscope, Type L Plug-in.

2. Tektronix C-12 Osc11loscope Camera 
3. Probe assembly designed and fabricated by BNW Testing Methods personnel

4. Sanborn Dual-Chiannel Strip Chart Recorder Model 320

5. Portable test tank and crystal manipulator for irradiated specimens

D. Test Specimeng

1. Flat and curved aluminum plates of various thicknesses

2. Sections of uniriadiated process tubes of varlous thicknesses

3. A process tube section with machined $0 . d_{\text {. }}$ steps in 0.004 in. increments to cover the thickness range from 0.019 in. to 0.067 in。

4. Mock-up reactor tube at 108-B Building -- composed of "newthickness" sections, a clear plastic section and eleven short sections of rarying thicknesses, all taped and clamped together to make one continuous tube. vertical and horizontal displacement of the tube's central regions were adjustable to simulate reactor tube's bowing and warp.

5. Reactor process tubes of "D" reactor: $\$ 4573,4583,1485$. Reactor process tubes of "B" reactor (mechanical tests only).

6. Cut-up pieses from reactor tube 14573 : top and bottom pleces at $7 \mathrm{ft} 9 \mathrm{in.}$ and $10 \mathrm{ft} 9 \mathrm{in.}$. from rear Van Stone flange. PRINCIPLE OF OPERATION.

A high frequency (about $22 \mathrm{MHz}$ ) crystal is pulsed with a narrow time duration (about $35 \mu \mathrm{sec}$ ) pulse. The resultant ultrasound pulse travels to the process tube wall where a portion of it reflects from the front surface. Another portion penetrates the wall and then reflects from the back surface-A part of this latter enersy trails the front surface echo back to the crystal. The spacing between the two pulses is a measure of the wall thickness. Analog 
circuits operate on the two pulses to provide a voltage readout - the amplitude of which is proportional to wall thickness. Readout voltage to a. recorder occurs at the pulse repetition rate (normally 2000 pulses/sec) enabling an independent thickness reading for every pulse. Averaging takes place at the instrument's thickness meter resulting in smooth indication. DEVELOPMENT PRECEDING IN-REACTOR TRIAL

\section{Ultrasonic Instrument - See Figure 49}

Circuit modifications were necessary to enable usage of $50 \mathrm{ft}$ cables connecting the pulser-amplifier to the probe crystal. Purpose of the modifications was to eliminate "ringing" of the cable and consequent false readouts, and was accomplished by impedance matching the instrument to the $70 \mathrm{ohm}$ cable. See Flgure 50 for an illustration of echo waveforms before and after impedance matching. Series inductive peaking was also added at the crystal end of the cable: about 0.8 Hhenry in shunt with 220 ohm resistance.

Amplifier modifications were made in an attempt to reduce a tendency to form a multiple peaked front surface echo. One RF amplifier stage was tuned, and defector and pulse amplifler stages' time constants were increased. See F1gures 51 and 52 for echo waveforms before and after amplifier modifications. Due to the nature of the amplifier's design and layout, more extensive modifications were not feasible (on leased equipment) and the problem of multiple peaked front surface echoes, although improved, was not ent1rely correcteà.

An additional small measure of improvement was observed by increasing water path from about $0.2 \mathrm{in}$. to about $0.4 \mathrm{in}$. A water path of about $0.2 \mathrm{in}$. is fixed in the present probe design, but in the event of redesign, water path should be increased to 0.4 to $0.5 \mathrm{in}$. 


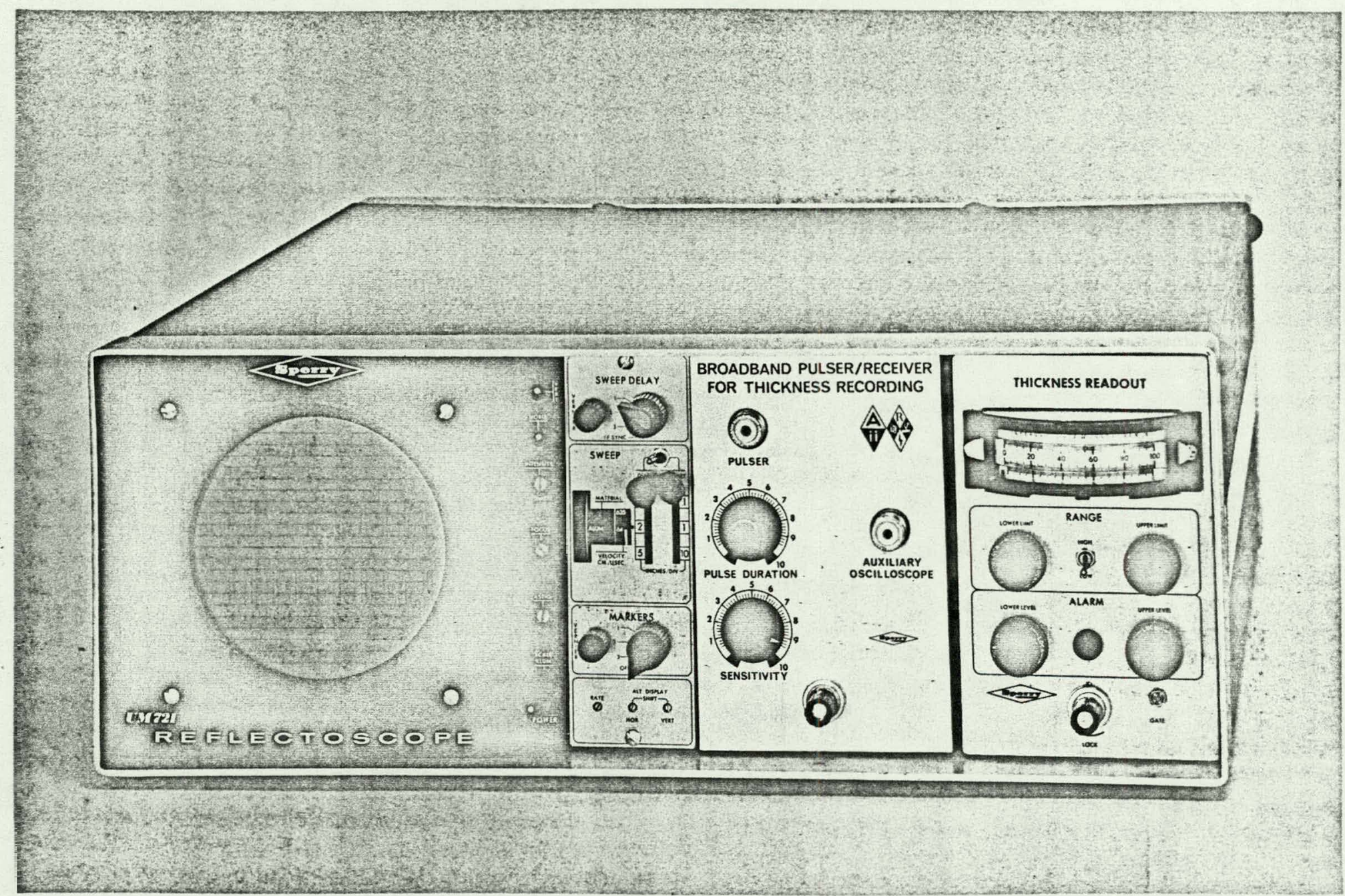

\section{FIGURE 49}

Sperry Ultrasonic Thickness Measurement Instrument 


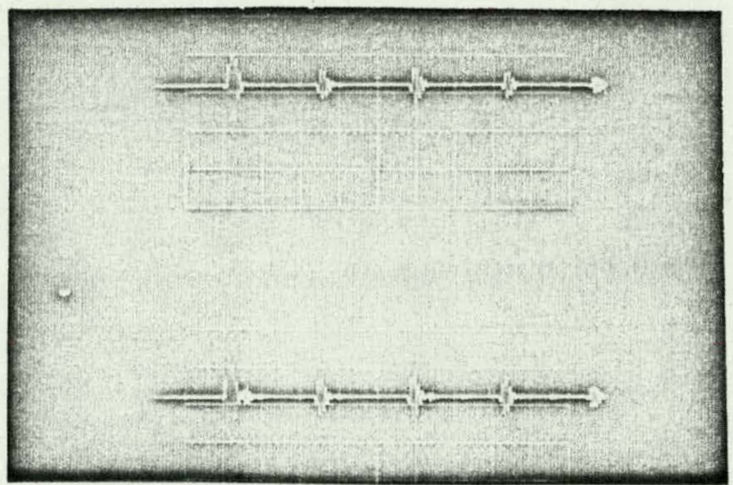

Top - RF Echo Pulses with Cable Impedance Matching

\section{Bottom - RF Echo Pulses Without Cable Impedance Matching}

FIGURE 50

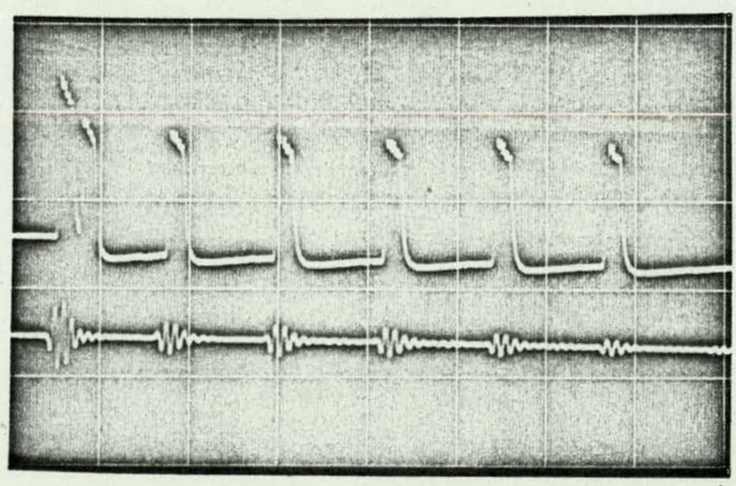

Reverberations with Multiple Peaked Front Surface Echo

Top - Video Output

Bottom - RF Output

FIGURE $5 \dot{1}$

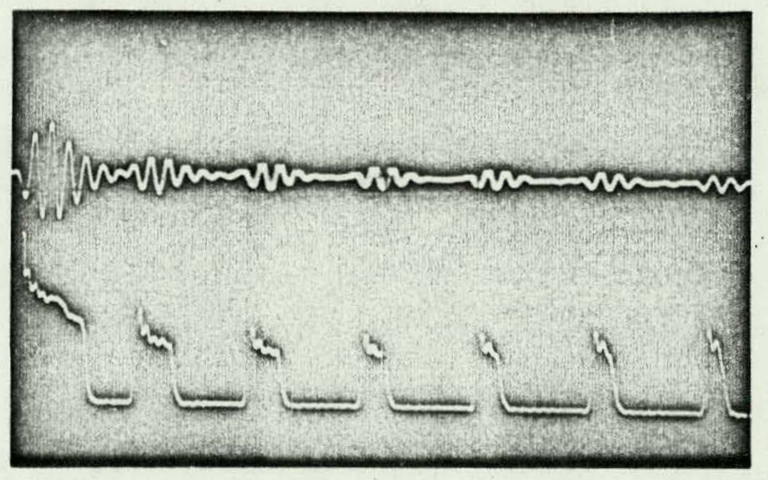

Reverberations with Single Peak Front Surface Echo - After Circuit Modifications Top - RF Output

\section{Bottom - Video Output}

0

FIGURE 52 


\section{Probe Design and Development}

The probe was designed to carry an array of eight crystals -5 on the top and 3 on the bottom. See Figures 53 and 54 for photos of the probe. Alignment was maintained by spring loaded shoes located on the top side of each end pushing the end blocks against the tube ribs. See Figure 55 for an illustration of an end block cross section. Fixed position guide blocks located within the ribs maintain circumferential position. The probe is assembled to be water tight; electrical matching networks are located within the probe body. Sealtight flexible electrical conduit is used to seal the probe end, protect the electrical cable, and provide a means to push and pull the probe through the reactor tubes. Distances were marked off at 6 in. increments so that position within the reactor could be determined. A nozzle adapter seals the end of a reactor tube while water pressure, inserted at the adapter, helps push the probe down the tube. Water flow is maintained during pull back to insure that continuous water coupling exists between crystals and tube that ultrasonic pulses may not be interrupted. Water channels located on the side of the end blocks are slanted so that water flow will assist the spring loaded shoes in maintaining probe alignment.

Difficulty was experienced during trial runs at the 108-B mock-up facility. The probe would frequently twist out of the ribs' guide track in thin wall regions and then become stuck when thicker wall regions were reached. As a result of these experiences, the fixed position guide block was widened and deepened, and the edges on the spring loaded shoe were rounded to permit freer rocking motion. In addition, stronger springs and rounded end guide blocks (See Figure 53) were made up but not used.

A noninstrumented probe trial was conducted at B-Reactor to evaluate probe design before the instrumented trial at D-Reactor was to be done. Although 
vii

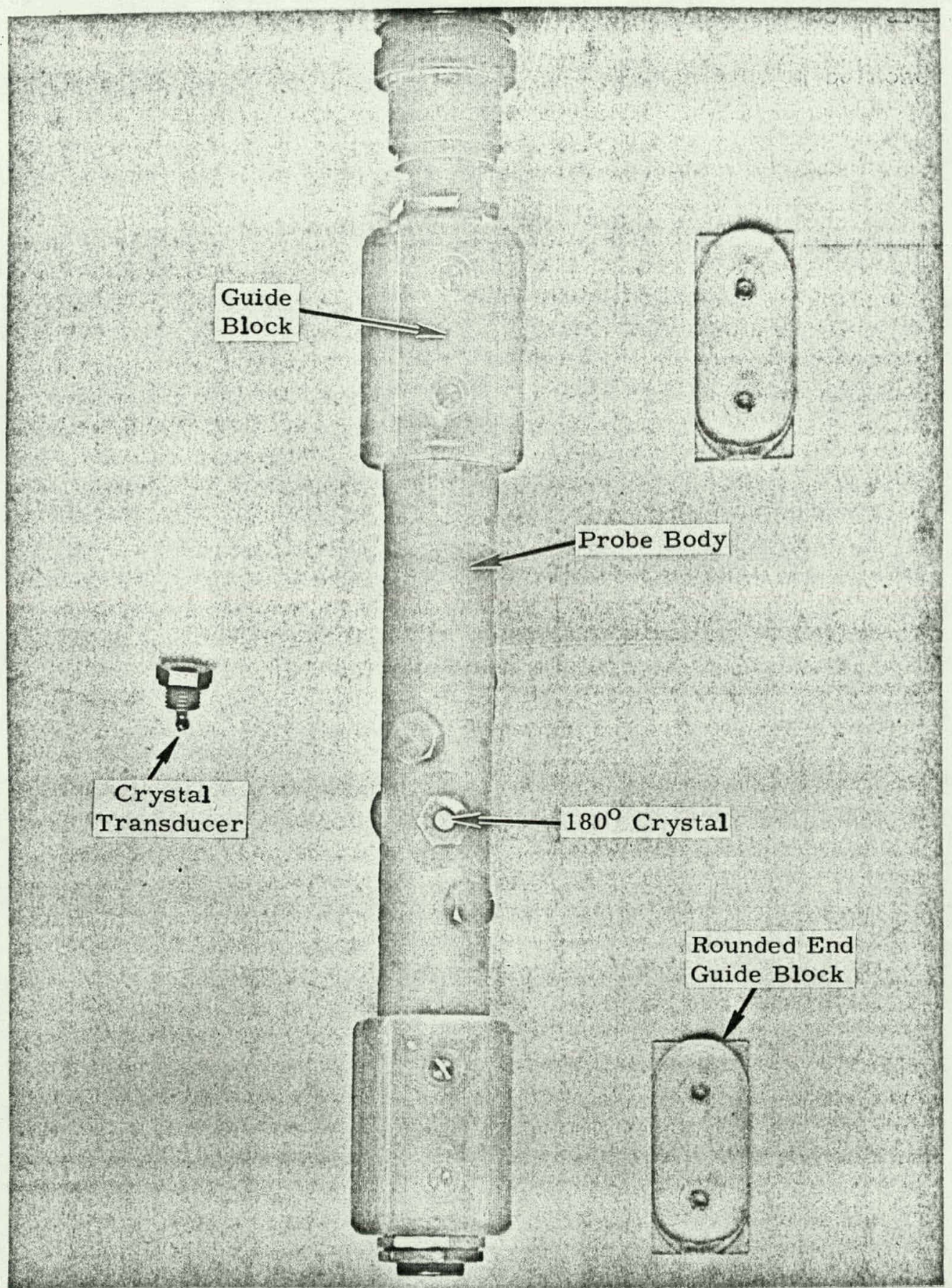

\section{FIGURE 53}

Wall Thickness Measurement Ultrasonic Probe - Probe Head 


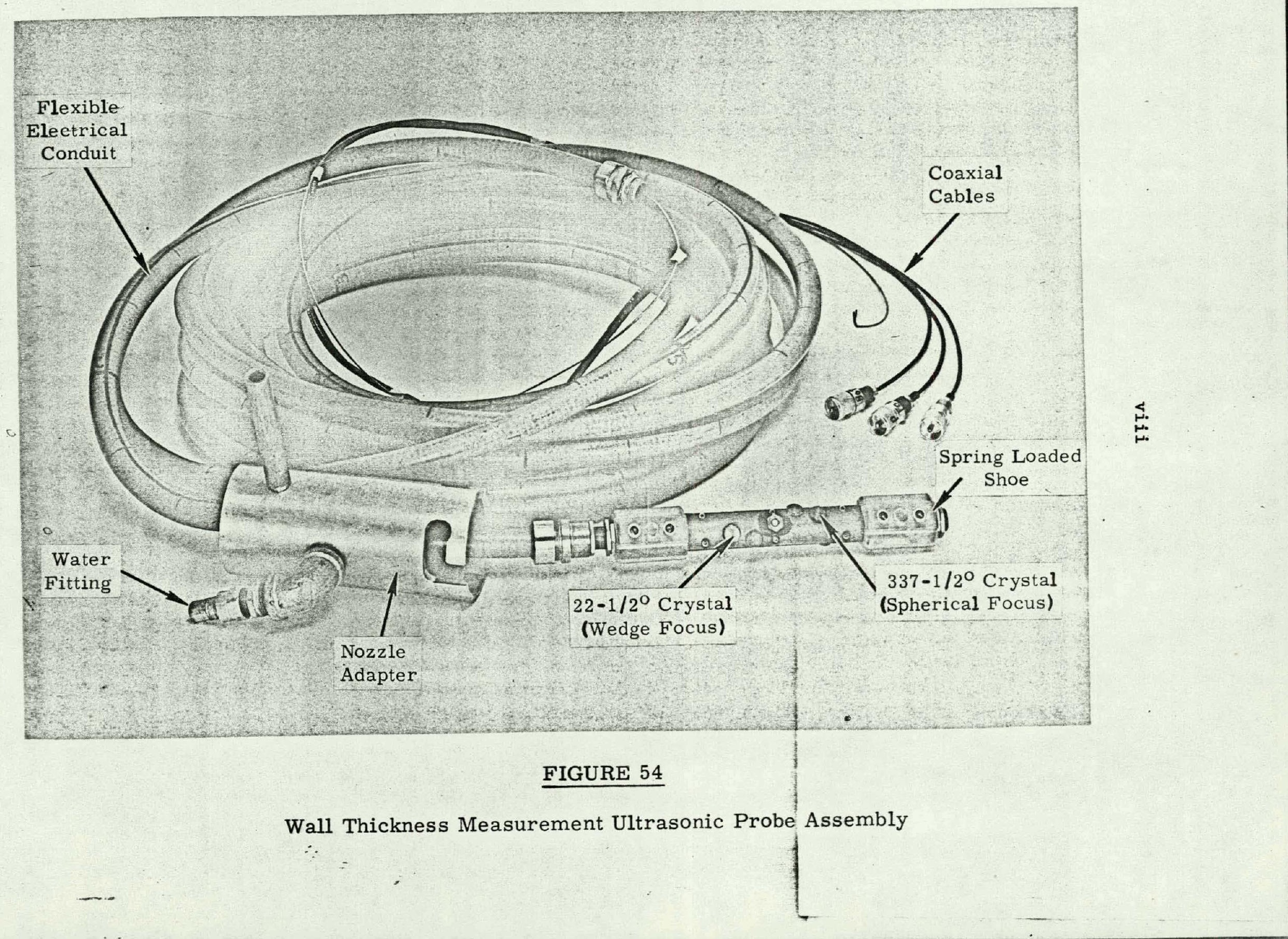




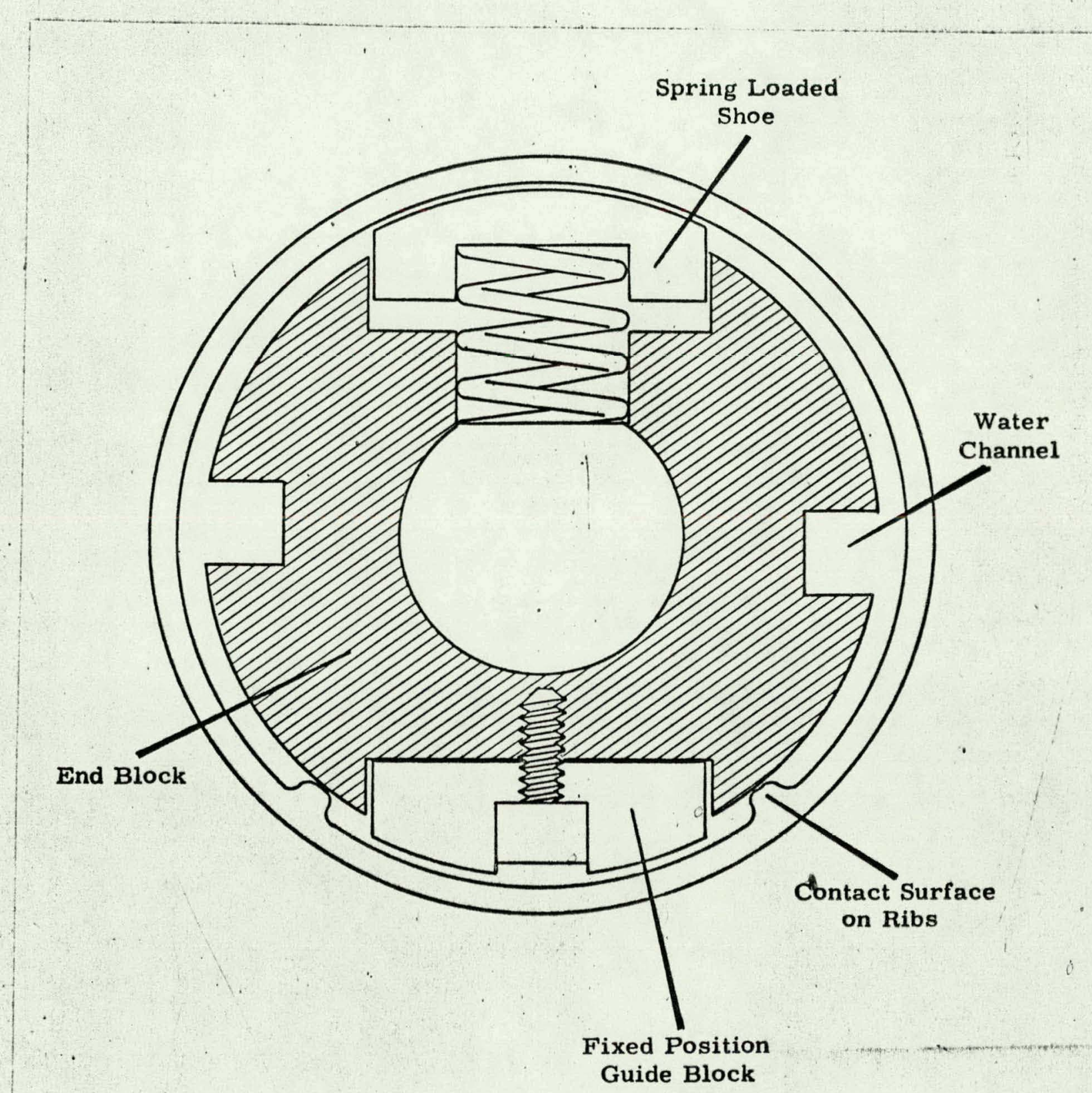

\section{FIGURE 55}

Wall Thickness Measurement Ultrasonic Probe - Support and Positioning Methods 
the probe became stuck in one of the six tubes trled, It was dislodged without damage and after minor modiffcations was judged to be of antlafactory design for the inotrumented trlal. Futuro probe sticking was to be minimlzed by keoping torsional forces on the probe at a minimum.

Although the probe was manually puohed and pulled throughout its varlous trials, a constant opeed mechanized puller 18 recommended for future usage 18 recordings are to be made.

Additional probe detalls may be found on Hanford drawling H-3-85872. Ultrasonic Crystal Transducers

Photos of the cryatals are seen In Flgures 53 and 54. Additional detallo may be found in Hanford drawing H-3-25873. Two of the cryotals used in the . reactor triel $\left(22-1 / 2^{\circ}\right.$ and $\left.180^{\circ}\right)$ were opherlcally focused whereas the $337-1 / 2^{\circ}$ crystal was wedge focubed with the lone axis in the longltudinal alrection. A algnificant roduction in multiple peaked front ourface echoes was noted by uelng the wedge focused crystel during a trial in the 108-B mook-up tube. Better resulti, In general, were also obtalned durling the renctor trial from the wodge focused oryotal than from the ophorically focused cryotal. Improver. ment 1. attributed to a reduced effoct from tube curvature. .

Laboratory Experiments

Laboratory experimonts were Intended to provide depth resolution data and to uncover posalble obstacles to the antlolpated Inireactor application. Readout accuracy 18. opec1f1ed by the manufacturex to be \pm 1 percent of the difference between upper limlt and lover limit nottings. The readout was noted to be accurate, but no attempt was wade to verify 1 percent accuracy. Not only was accuracy oapablilty conoldered to be of secondary 1mportance durIng the dovelopment phase, but also there 18 some amblgulty exceeding i percent normaliy attached to measuremonts on pltted ourved surfaces. 
Measurements were successfully taken on flat and curved aluminum specmens as thin as 0.019 inch. See Figure 56 for a recording of a process tube sample with sections machined in 0.004 . in. 1ncrements. The manufacturer provided a chart recording as evidence that the instrument could measure as thin as 0.016 inch. Aluminum specimens as thick as 0.125 inch were also measured. 0.125 inch is by no means an upper limit, but merely the thickest specimen used during laboratory experiments.

\section{8-B Mock-Up Experiments}

A slmulated reactor process tube was made avallable at 108-B Building. The tube consisted of eleven small aluminum sections and a clear lucite section taped to each other and also to longer sectlons, one of whlch was attached to a front face gun barrel. Thicknesses of the sections varied from about 0.031 Inch to about $0.064 \mathrm{Inch}$. The sections are supported in such a manner that up to about 2 inches of curvature can be put into the assembled tube to simulate drooping and buckling that exists in actual reactor tubeg. A large number of trials were made at the facility. Probe mechanical improvements were made as a result of early tests. Some instrument modifications were also made based on findings from mock-up experiments. See Figure 57 for a recording of the bottom part of the mock-up tube. 


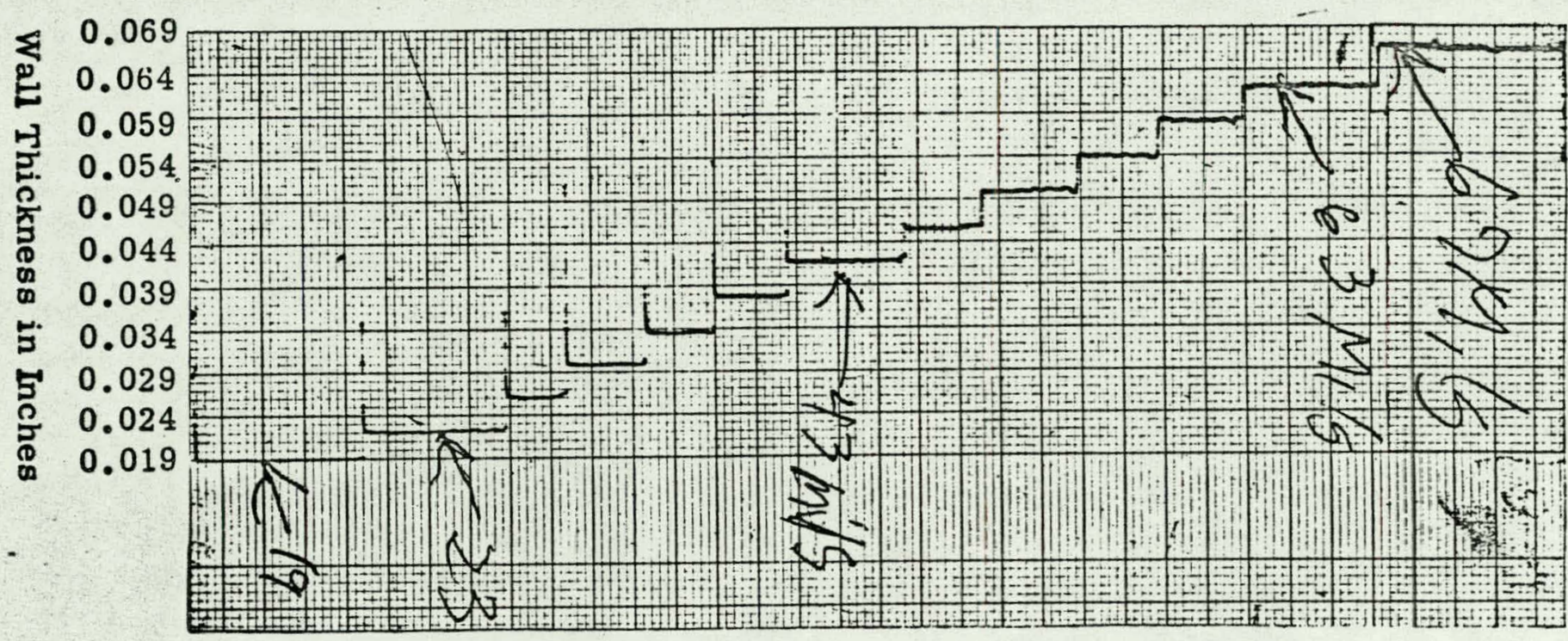

\section{FIGURE 56}

Recording of a Process Tube Section with O.D. Machined in 0.004 in. Steps 

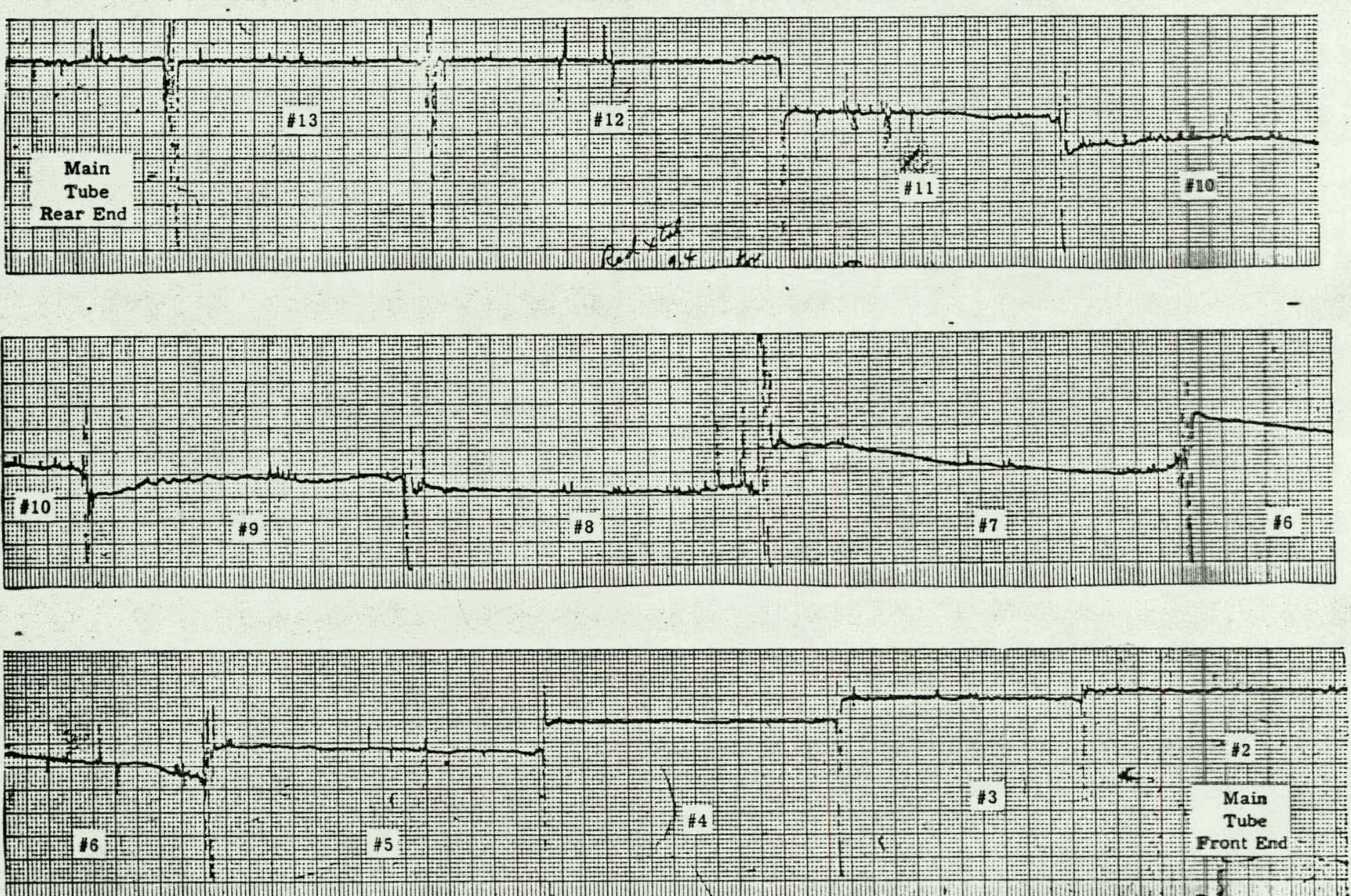
T

\section{FIGURE 57}

Recording of Bottom ( $180^{\circ}$ Crystal) of 108B Mock-up Tube 


\section{BIBLIOGRAPHY}

1. Letter from C. G. Lewis to D. C. Worlton, August 27, 1964.

2. R。 L。 Brown Jr., TM-MEMO-64-18, Review of the Sector Wall Th1 ckness Gauge, September 24, 1964.

3. Letter from L. V. Barker to D. C. Worlton, October 9, 1964.

4. Letter from J. C. Spanner to C. G. Lewis, October 21, 1964.

5. Letter from J. C. Spanner to C. G. Lewis, January 25, 1965.

6. Letter from R. L. Brown Jr. to J. R. Splnk, January 25, 1965.

7. R. L。 Brown Jr., TM-MEMO-65-1, Study of Feasibility of Aluminum Process Tube Wall Thickness Measurement, February 1, 1965.

8. Letter from C. G. Lewis to J. C. Spanner, February 16, 1965.

9. D. O. Hunter, Trip Report, BNWL-CC-168, July 11, 1965.

10. Letter from C. E. Bowers to J. C. Spanner. Auguot 23, 1965.

11. D. O. Hunter, Trip Report, Testing Methods Engineering, September 17, 1965.

12. Letter from B. E. Dozer to C. E. Bowers, October 6, 1965.

13. Letter from D. O. Hunter to C. E.,Bowers, April 12, 1966.

14. Letter from D. O. Hunter to C. E. Bowerg/C. B. Organ, May 9, 1966.

15. Laboratory Record Book, BNW-234., D. O. Hunter.

16. Monthly Report Notebook, D. O. Hunter, May 1965 through June 1966. 